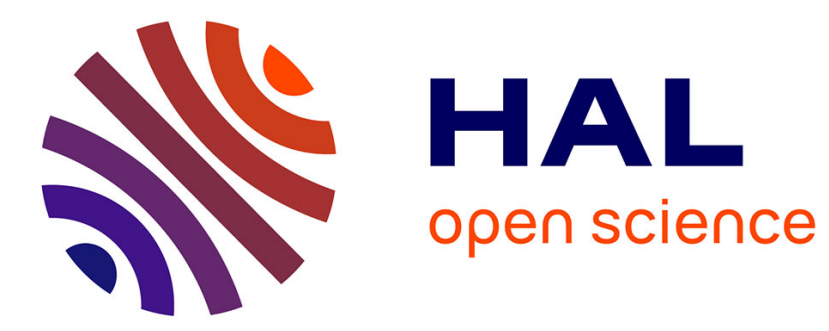

\title{
Optimum income taxation and layoff taxes
}

Pierre Cahuc, André Zylberberg

\section{To cite this version:}

Pierre Cahuc, André Zylberberg. Optimum income taxation and layoff taxes. Journal of Public Economics, 2008, 92 (10-11), pp.2003-2019. 10.1016/j.jpubeco.2007.12.006 . halshs-00255794

\section{HAL Id: halshs-00255794 https://shs.hal.science/halshs-00255794}

Submitted on 14 Feb 2008

HAL is a multi-disciplinary open access archive for the deposit and dissemination of scientific research documents, whether they are published or not. The documents may come from teaching and research institutions in France or abroad, or from public or private research centers.
L'archive ouverte pluridisciplinaire HAL, est destinée au dépôt et à la diffusion de documents scientifiques de niveau recherche, publiés ou non, émanant des établissements d'enseignement et de recherche français ou étrangers, des laboratoires publics ou privés. 


\title{
Optimum Income Taxation and Layoff Taxes*
}

\author{
Pierre Cahuc ${ }^{\dagger}$ \\ CREST-INSEE, Université Paris 1, CEPR, IZA. \\ André Zylberberg \\ EUREQua-Université Paris 1 and CNRS
}

July 2005 (first version: June 2004)

\begin{abstract}
This paper analyzes optimum income taxation in a model with endogenous job destruction that gives rise to unemployment. It is shown that optimal tax schemes comprise both payroll and layoff taxes when the state provides public unemployment insurance and aims at redistributing income. The optimal layoff tax is equal to the social cost of job destruction, which amounts to the discounted value of the sum of unemployment benefits (that the state pays to unemployed workers) and payroll taxes (that the state does not get when workers are unemployed). Our quantitative analysis suggests that the introduction of layoff taxes, that are usually absent from actual tax schemes, could lead to significant increases in employment and GDP.
\end{abstract}

KEYW ORDS: Layoff taxes, Optimal taxation, Job destruction.

JEL CODES: H21, H32, J38, J65

${ }^{*}$ We wish to thank, without implication, Guy Laroque and Bernard Salanié for very helpful comments. We also thank participants in seminars at CREST, Université de Paris 1, Université d'Aix-Marseille 2, Norwegian School of Economics and Business Administration and CERGE.

${ }^{\dagger}$ Corresponding author: CREST-INSEE, Timbre J 360, 15, Boulevard Gabriel-Peri, 92245, Malakoff, France. Email: cahuc@ensae.fr. 


\section{Introduction}

So far, the influence of taxes on job creation and destruction has been neglected to a large extent by the economics of taxation (see Salanié, 2003, for a recent survey). Yet, many empirical studies have shown that modern economies face dramatic job turnover that influences employment and growth. From this point of view it is important to analyze the impact of taxes on job creation and destruction. In a seminal paper, Feldstein (1976) argued that payroll taxes used to finance unemployment benefits in most OECD countries induce too many layoffs, because employers do not take into account the cost of insurance provided by the state to the unemployed workers. To avoid this excess of job destruction unemployment insurance has to be financed by layoff taxes. The experience rating system used in the United States is an example of layoff taxes that induce firms to internalize the cost associated with their layoff decisions (Burdett and Wright, 1989a, b, Anderson and Meyer, 1993, 2000, Blanchard and Tirole, 2004, Cahuc and Malherbet, 2004).

In this paper, it is argued that layoff taxes are not only a natural counterpart to the state provision of unemployment benefits: they are also a natural counterpart to other public expenditures. Indeed, when employers destroy a job, they do not take into account that workers who are fired will continue to consume collective goods but may contribute to a much smaller extent to finance these goods. In this context, if individuals bring less in the budget of the state when they are unemployed than when they are employed, the social value of jobs, that is their value for the entire society, is larger than their private value, that is their value for the worker and the employer. This phenomenon can lead to excessive job destruction in the absence of layoff taxes. Therefore, layoff taxes should not be only a part of the unemployment insurance system. They should also be integrated as an instrument in the overall tax system used to finance public expenditures.

We explore this idea in the standard approach of optimal taxation models (Mirrlees, 1971) 
which analyzes the tax-subsidy schemes that implement second-best allocations when the state has incomplete information about the preferences of individuals. More precisely, we follow the approach of Diamond (1980) in which individuals, whose only decision is whether to work or not, differ in their taste for leisure as well in ability (see also: Beaudry and Blackorby, 1997, Choné and Laroque, 2005, Laroque, 2005, Saez, 2002). In Diamond's model, the ability of employees, which determines the market income and then the level of taxes, is observable, but taste for leisure is private information. In our paper, Diamond's model is enriched in order to account for unemployment and job destruction. It is assumed that the productivity of each job depends on the ability of the worker, that is common knowledge only when he participates in the labor market, and a random job specific productivity shock, that is privately known by the firm and the worker once the worker has been recruited. Moreover, firms are risk neutral, workers are risk averse and it is assumed that unemployment insurance is provided by the state. ${ }^{1}$ In this context, some workers who have decided to participate in the labor market are unemployed because jobs whose productivity is too low are destroyed.

Our paper analyzes the optimal tax-subsidy schemes that implement second-best allocations when there is job destruction. The main result is that optimal tax schemes comprise both payroll and layoff taxes when the state provides public unemployment insurance and aims at redistributing income. It turns out that the optimal layoff tax is equal to the social cost of job destruction, which amounts to the discounted value of the sum of the unemployment benefits (that the state pays to unemployed workers) and payroll taxes (that the state does not get when

\footnotetext{
${ }^{1}$ The "implicit contract literature" has shown that risk neutral firms fully insure workers against income fluctuations by giving constant wages to the employees and unemployment benefits to the workers they layoff (Baily, 1974, Azariadis, 1975, Rosen 1985, Pissarides, 2001), However, in the real world, unemployment insurance is not provided by firms. Some rare exceptions are presented and discussed by Chui and Karni (1998) who stressed that the failure of the private sector to provide unemployment insurance can be explained by the interaction of adverse selection and moral hazard problems: an isolated firm that would offer private insurance would attract workers with strong work aversion, who would try to be fired as soon as they become eligible to the unemployment benefits. If work aversions are not observable and the level of effort of the employees not verifiable, it can be the case that private unemployment insurance cannot emerge. In our paper, we assume, like Burdett and Wright (1989a,b) and Blanchard and Tirole (2004) among many others, that unemployment insurance is provided by the state.
} 
workers are unemployed).

This result is obtained in two steps. In the first step, we consider a static framework which allows us to get a set of intermediary results. More precisely, if the state does not aim at redistributing income across individuals with different abilities, it is shown that first-best allocations can be reached thanks to unemployment benefits that are entirely financed by layoff taxes. This is a simple generalization of the result obtained by Blanchard and Tirole (2004) in a model without participation decision and heterogeneity of workers. If the state aims at redistributing income across individuals with different abilities, first-best allocations cannot be reached because the taste for leisure is private information. In that case, it is shown that second-best allocations are obtained thanks to tax-subsidy schemes that comprise layoff taxes equal to the sum of the unemployment benefits and the payroll tax raised on the production of the employees.

Then, in the second step, the properties of optimal tax-subsidy schemes are derived in a dynamic version of the static model. This dynamic version is useful to give quantitative insights on the optimal amount of layoff taxes and on their impact on employment, unemployment, GDP, welfare and the budget of the state.

The paper is organized as follows. The preferences, the technology and the first-best allocations of the static benchmark economy are presented in section 2. Section 3 is devoted to the analysis of the tax-subsidy schemes that allow the state to reach second-best allocations. Section 4 provides a dynamic extension of the benchmark model. The dynamic model is utilized to yield quantitative evaluations of the impact of layoff taxes in section 5. Section 6 concludes.

\section{The Benchmark Model}

\subsection{Preferences and technology}

We consider a static economy with a continuum of individuals whose size is normalized to one. There are two goods: labor and a marketable good produced thanks to labor. Individuals outside 
the labor force do not produce the marketable good. Individuals inside the labor force can be either employed or unemployed.

An individual is described by a set of exogenous characteristics, denoted by $s=(y, z)$; where $y$ stands for his ability and $z$ for his taste for leisure. We assume that $(y, z)$ has a joint density $h(y, z)$ with $h>0$ over the support $S \subset\left[y_{\min },+\infty\right) \times \mathbb{R}, h$ is continuous. The preferences of the type- $s$ individual are represented by the utility function $v(c+z \ell)$, twice derivable, increasing and strictly concave, where $c \geq 0$ denotes consumption, $\ell \in\{0,1\}$ denotes leisure that amounts to zero if the individuals is active (either employed or unemployed) and to one if he is not in the labor force. The set of inactive individuals is denoted by $S_{I}$ and the set of active agents (which comprises employed and unemployed workers) is denoted by $S_{A}$.

Creating a job for a type- $(y, z)$ individual entails a fixed cost denoted by $k(y)>0$. When such an individual gets a job, he can produce $x \cdot y$ units of the marketable good where $x \in \mathbb{R}$ is an idiosyncratic shock drawn in a distribution with a continuous differentiable cumulative distribution function denoted by $G$. Each individual can occupy at most one job.

An allocation defines the consumption and the employment status of all the agents of the economy. It is a mapping that associates to each type-s individual, conditional on the realization of the productivity shock $x$ for active individuals, his consumption: $c(s)$, if $s \in S_{I}, c(s, x)$ if $s \in S_{A}$, and his employment status: inactive $(\ell(s)=1)$, employed $(\ell(s)=0$ and marketable production $=x \cdot y)$ or unemployed $(\ell(s)=0$ and marketable production $=0)$. The choice between employment and unemployment amounts to define the set of values of the productivity parameter $x$, denoted by $W(y) \subset \mathbb{R}$, for which the type- $(y, z)$ individuals who belong to $S_{A}$ work.

All allocations have to satisfy the feasibility constraint:

$$
\int_{S_{A}}\left[Y(y)-\int_{\mathbb{R}} c(y, z, x) d G(x)\right] h(y, z) d y d z=\int_{S_{I}} c(y, z) h(y, z) d y d z,
$$

where $Y(y)=y \int_{W(y)} x d G(x)-k(y)$ stands for the average net production of employees with 
ability $y$.

\subsection{First-best allocations}

First-best allocations are chosen by a fully informed planner who has complete information on the pair $s=(y, z)$ describing each agent's characteristics and on the productivity shocks $x$. First-best allocations are such that there are no other feasible allocations that can improve the welfare of at least one agent without worsening the welfare of the others. When an agent faces risky outcomes - this will be the case for the active agents -, it is assumed that feasible allocations are ranked according to the expected utility criterion conditional on characteristics $(y, z)$. The time sequence of events that describes the decision of the planner runs as follows:

1) The planner decides which set of agents $s \in S_{I}$ are inactive $(\ell(s)=1)$, and which set of agents $s \in S_{A}$ are allowed to participate in the production of the consumption good $(\ell(s)=0)$. The planner also announces the consumption of the marketable good of every type- $s$ individuals. The consumption can be conditional on the realization of the productivity shocks for active individuals.

2) Every individual in $S_{A}$ makes a draw $x$ from the cdf function $G$ that raises his potential production to the level $x \cdot y$. After observing $x$, the planner decides whether each individual in $S_{A}$ actually produces or not (this is the job destruction decision). Individuals produce and consume according to the plan announced at step 1).

The first-best allocations can be obtained by backward induction.

At step 2), once $x$ has been drawn, it is worthwhile keeping employed the individuals who produce more on-the-job than in unemployment, i.e. it is worthwhile keeping employed the type$(y, z)$ workers such that $x \cdot y \geq 0$. Therefore, the choice of the set of values of the productivity parameter $x$, denoted by $W(y) \subset \mathbb{R}$, for which the type- $(y, z)$ individuals who belong to $S_{A}$ work, boils down to the choice of the reservation productivity below which the type- $(y, z)$ individuals belonging to $S_{A}$ are unemployed. The first-best reservation productivity, denoted by $X^{*}$, satisfies 
the productive efficiency condition:

$$
X^{*}=0
$$

Since it $\operatorname{costs} k(y)$ to assign the type- $(y, z)$ individual to $S_{A}$, the average net first-best production of an individual with ability $y$ belonging to $S_{A}$ amounts to $Y^{*}(y)=-k(y)+y \int_{0}^{+\infty} x d G(x)$.

At step 1) the planner has to choose the consumption of the marketable good for every individual. The consumption of inactive individuals can only depend on their type $s$. For the active individuals, the assumption of risk aversion implies that the certainty equivalent income of the lottery $\{c(s, x)\}$ is smaller than the expected consumption $\int_{\mathbb{R}} c(s, x) d G(x)$. Accordingly, a social planner whose decisions are based upon the expected utility criterion can always save resources by providing to the type-s individuals belonging to $S_{A}$ the certainty equivalent associated with the lottery $\{c(s, x)\}$. It follows that the first-best allocations necessarily insure all individuals in $S_{A}$ against productivity shocks and give them the same consumption whether employed or unemployed.

At step 1), the planner also chooses the set of individuals who participate in the labor market. It can easily be understood that the set $S_{A}$ of active agents only comprises type- $s$ individuals such that $Y^{*}(y) \geq z$. Imagine that we can find in $S_{A}$ an agent with $Y^{*}(y)<z$. This agent can get the same utility level when he is inactive if his consumption of the marketable good is decreased by $z$. This allows the social planner to win $z$ and lose $Y^{*}(y)$ as forgone production, which yields a positive net gain equal to $z-Y^{*}(y)$. Thus, it is not optimal to have an active individual whose taste for leisure is larger that his expected production. An analogous reasoning shows that the set $S_{I}$ comprises type-s individuals such that $Y^{*}(y)<z$. In other words, the participation decision reads:

$$
\ell^{*}(y, z)=\left\{\begin{array}{l}
0 \text { if } z \leq Y^{*}(y)=-k(y)+y \int_{0}^{+\infty} x d G(x) \\
1 \text { otherwise. }
\end{array}\right.
$$

The properties of the first-best allocations are summarized in the following proposition: 
Proposition 1 A feasible allocation is a first-best allocation if and only if:

1. Active individuals are employed when $x \geq 0$ and unemployed otherwise.

2. Every agent with the same type s belonging to the set $S_{A}$ of active individuals gets the same consumption level whatever the value of $x$.

3. The set $S_{A}$ of active individuals comprises all the type-s individuals such that $Y^{*}(y) \geq z$, and the set $S_{I}$ of inactive individuals comprises all the agents such that $Y^{*}(y)<z$.

Proof. see appendix A.

Claim 3 of proposition 1 is a particular case of a more general result established in Laroque (2005) stating that in an economy with labor supply choice at the extensive margin, where the agents choose whether to work or not to work, it is Pareto optimal that someone works if and only if his productivity is larger than the extra necessary income to compensate him for the hardship of work. In our economy, the agents are perfectly insured against unemployment risks and the extra necessary income to compensate an individual, with taste for leisure $z$, for being active is simply equal to $z$ while his expected productivity amounts to $Y^{*}(y)$.

\section{Second-best allocations and optimal tax-subsidy schemes}

This section is devoted to the design of optimal fiscal policies in a framework in which the state is committed to a tax-subsidy scheme and where the marketable good is produced on a perfectly competitive market. Contrary to the first-best environment, the state does not observe the characteristics of the agents. Namely, the taste for leisure $z$ always remains private information of the worker. The ability $y$ and the idiosyncratic productivity shock $x$ are observed by the firm and the worker but are not verifiable. The distributions of $x, y$ and $z$ are common knowledge. The state only observes the labor contracts and whether individuals work. This implies that the state knows who has been fired and is able to distinguish unemployed workers from inactive 
individuals. In this situation, the tax-subsidy scheme can only depend on the elements of the labor contracts and on the employment status (employed, unemployed, inactive).

First, the decentralized equilibrium is studied. Then, we analyze the optimal policies.

\subsection{Decentralized equilibrium}

The marketable good is produced by firms on a competitive market with free entry. As the labor contracts only stipulate wages, the state can use tax-subsidy schemes conditional on three elements: 1) the wage, denoted by $w ; 2$ ) the employment status (employed, unemployed or inactive); 3) the job destruction decision. Accordingly, the tax-subsidy scheme can comprise a payroll (or income) tax, $\tau(w)$, a layoff tax, $f(w)$, unemployment benefits $b(w)$, and a income guarantee $\rho$ paid to the inactive persons. In this framework, the overall consumption of the individual who has signed a labor contract that stipulates a wage $w$ amounts to $w$ if he is employed and to $b(w)$ if he is unemployed. The type- $(y, z)$ individual that does not participate in the labor market gets a utility level $v(z+\rho)$. The wage $w$ entails labor costs equal to $w+\tau(w)$ if workers remain employed and to $f(w)$ if they are fired.

The time sequence of events runs as follows:

1) The state announces a balanced budget tax-subsidy scheme $\{\tau(w), f(w), b(w), \rho\}$.

2) Individuals decide whether they belong to the labor force or stay inactive. ${ }^{2}$

3) Employers enter into Bertrand competition to hire workers.

4) The specific productivity shocks $x$ occur and employers decide whether they keep the workers or they destroy the jobs. Then, employers pay the wage and the payroll tax for every continuing job. Every destroyed job gives rise to the payment of layoff taxes. Employed workers get a wage $w$, unemployed workers get unemployment benefits $b(w)$ and inactive individuals get the garantee income $\rho$.

\footnotetext{
${ }^{2}$ It is assumed that individuals who decide to belong to the labor force reveal their true productivity. If they have the possibility to behave as agents of lower productivity without cost, thruthful revelation would only obtain under the condition that their wage $w$ be non decreasing in $y$, a condition that will be satisfied in equilibrium.
} 
In this subsection, we characterize the existence and the properties of the competitive equilibrium of the labor market for the tax-subsidy scheme announced at step 1). This problem can be solved by backward induction.

At step 4) firms destroy jobs if and only if their profits, $x \cdot y-w-\tau(w)$, are lower than their destruction costs, $-f(w)$. The job destruction decision boils down to the choice of a reservation value of the productivity parameter $x$, denoted by $X(w, y)$, below which job are destroyed. ${ }^{3}$ The reservation productivity reads:

$$
X(w, y)=[w+\tau(w)-f(w)] / y
$$

For individuals with ability $y$, the job destruction rate (or equivalently the unemployment rate), denoted by $q(w, y)$, is equal to $G(X(w, y))$.

At step 3), the expected profit of an employer offering a contract $w$ to a type- $(y, z)$ worker, denoted by $J(w, y)$, reads:

$$
J(w, y)=-k(y)+\int_{X(w, y)}^{+\infty}[x \cdot y-w-\tau(w)] d G(x)-q(w, y) f(w) .
$$

Existence and unicity of the Bertrand equilibrium depend on the properties of the functions $k(\cdot)$ and $G(\cdot)$ and of the functions $\tau(\cdot), b(\cdot), f(\cdot)$ describing the tax-subsidy schedule. We shall assume that all these functions are such that the expected profit $J(w, y)$ satisfies the properties summarized in Assumption 1:

\section{Assumption 1}

1.i) $\forall y,\{w \geq 0 \mid J(w, y)=0\} \neq \emptyset$.

1.ii) $\forall y, \lim _{w \rightarrow+\infty} J(w, y)<0$.

\footnotetext{
${ }^{3}$ This behavior comes from the assumption that the reservation value of the productivity parameter $x$ is not contractable and that the firm cannot commit ex-ante to this reservation value by keeping aside funds to be paid to a third party in case of layoff. See the discussion in Blanchard and Tirole (2004).
} 
Conditions 1.i) and 1.ii) are necessary and sufficient conditions to obtain a unique Bertrand equilibrium with positive finite wages. ${ }^{4}$ More precisely, condition 1.ii) prevents employers from offering unbounded wages, thus Bertrand competition between the employers drives expected profits to zero and condition 1.i) states that for any $y$ there exists at least one positive wage giving an expected profit equal to zero. Then the Bertrand equilibrium wage is the highest value of $w$ that solves the zero profit condition $J(w, y)=0$. In other words, conditions 1.i) and 1.ii) imply that there exists a unique equilibrium wage contract $w(y)$ offered to the type- $(y, z)$ workers, which reads:

$$
w(y)=\sup \{w \geq 0\} \mid J(w, y)=0\} .
$$

Furthermore, we can obtain a precise result concerning the monotonicity of the equilibrium wage function $w(y)$ if we add the following (reasonable) assumption.

\section{Assumption 2}

2.i) $\forall y, J(w, y)$ is continuous in $w$.

2.ii) $\forall w, J(w, y)$ is strictly increasing with respect to $y$.

Proposition 2 When Assumptions 1 and 2 are satisfied there exists a unique equilibrium wage function $w(y)$ which is strictly increasing with respect to the ability level $y$.

Proof. According to 2.ii), for any $y^{\prime}>y$ the Bertrand equilibrium wage $w(y)$ corresponding to the ability level $y$ satisfies $J\left(w(y), y^{\prime}\right)>0$. The limit condition 1.ii) and the continuity condition 2.i) then imply that there exists (at least) one finite wage $w>w(y)$ such that $J\left(w, y^{\prime}\right)=0$. Finally, the definition (6) of the Bertrand equilibrium wage entails that the Bertrand equilibrium wage $w\left(y^{\prime}\right)$ corresponding to the ability $y^{\prime}>y$ is such that $w\left(y^{\prime}\right) \geq w>w(y)$.

\footnotetext{
${ }^{4}$ In our model the possibility of negative wages is ruled out for the agents cannot borrow and do not have any initial resources. Thus, they cannot pay for having a job.
} 
At step 2), the type-(y,z) individuals decide to enter into the labor market if and only if the participation constraint ${ }^{5}$

$$
[1-q(w, y)] v(w)+q(w, y) v[b(w)] \geq v(z+\rho)
$$

is fulfilled. This condition implies that only individuals whose taste for leisure $z$ is smaller than the threshold value, $Z(w, y)$, defined by

$$
v[Z(w, y)+\rho]=[1-q(w, y)] v(w)+q(w, y) v[b(w)]
$$

belong to the labor force. $Z(w, y)$ can be interpreted as the financial incentives to work provided to type- $(y, z)$ individuals.

In other words, the participation decision for a type- $(y, z)$ worker receiving a wage offer $w$ reads:

$$
\ell(y, z)=\left\{\begin{array}{cc}
0 & \text { if } \quad z \leq Z(w, y) \\
1 & \text { if } \quad z>Z(w, y)
\end{array}\right.
$$

Eventually, given any tax-subsidy scheme $\{\tau(w), f(w), b(w), \rho\}$ that satisfies Assumptions 1 and 2 , there exists a single decentralized equilibrium that defines an allocation entirely characterized by three functions of $y$ : the wage $w(y)$ (equation (6)) which accrues to type- $(y, z)$ employees, the financial incentives to work $Z(w(y), y)$ (equation $(7))$ and the reservation productivity $X(w(y), y)$ (equation (4)) below which jobs are destroyed.

\subsection{Optimal tax-subsidy schemes}

At decentralized equilibrium, the welfare of each individual is influenced by the tax-subsidy scheme chosen by the state. We shall use a Pareto criterion to define the optimal policies. By definition, a tax-subsidy scheme is optimal if it is feasible (i.e. satisfies the budget constraint of the state) and if there is no other feasible tax-subsidy scheme that can improve the welfare of at least one agent without worsening the welfare of the others. In other words, optimal tax-subsidy

\footnotetext{
${ }^{5}$ It should be noted that when Proposition 2 is satisfied, any active worker has interest to reveal his true ability.
} 
schemes implement second-best allocations. Like in the first-best environment, second-best allocations must satisfy efficiency conditions concerning the insurance against unemployment risk, the job destruction decisions, and the choice between activity and inactivity. In the sequel, we characterize more intuitively than rigorously the properties of second-best allocations. A formal proof of all these properties is given in Appendix B.

\section{Insurance}

It can easily be understood that efficiency requires that the state, which provides the unemployment benefits $b(w)$, must insure the active agents against unemployment risks. The expected utility of an agent who accepts a contract offering a wage $w$ amounts to $(1-q) v(w)+q v(b(w))$. Risk aversion implies that the certainty equivalent income of the lottery $\{w, b(w), q\}$ is smaller than the expected consumption $(1-q) w+q b(w)$. Therefore, the state can always save resources by designing a tax-subsidy scheme that provides to any active agent the certainty equivalent of his income whether he is employed or unemployed. Hence, any optimal policy satisfies:

$$
b(w)=w .
$$

\section{Job destruction}

Alike what happens in the first-best environment, efficiency requires the productive efficiency condition (2) to be satisfied. The reason is that it is not worth having an individual employed and producing $x \cdot y<0$. As individuals are fully insured against the unemployment risk, they get the same utility level whether employed or unemployed, but the overall production is larger when jobs producing $x \cdot y<0$ are destroyed (because the production of an unemployed is equal to 0 ). Looking at the market value of the reservation productivity given by equation (4), it follows that any optimal policy has to satisfy:

$$
w+\tau(w)-f(w)=0
$$


In such circumstances, one has $X(w(y), y)=X^{*}=0$ and the equilibrium job destruction rate is equal to $q(w(y), y)=G(0)$, and the average net production of an active individual of ability $y$ is worth $Y^{*}(y)=-k(y)+y \int_{0}^{+\infty} x d G(x)$.

\section{Participation decisions}

The efficiency requirement on participation decisions amounts to impose constraints on the financial incentives to work $Z(w(y), y)$ that will be denoted as $Z(y)$. The simple idea here, recently put to the fore by Laroque (2005), is that feasible allocations can be second-best if and only if individuals are not overtaxed. This result can be understood by looking at the relation between the budget of the state and the financial incentives to work. The net surplus that the state gets from individuals of ability $y$, denoted by $B(y)$, is equal to the production of active individuals minus their financial incentives to work, minus the cost of the income guarantee. Specifically: ${ }^{6}$

$$
B(y)=\left[Y^{*}(y)-Z(y)\right] H[y, Z(y)]-\rho \int_{-\infty}^{+\infty} h(y, z) d z,
$$

where $H(y, Z)=\int_{-\infty}^{Z} h(y, z) d z$ denotes the distribution of the tastes for leisure conditional on the ability $y$ of individuals, or, in other words, the labor force participation rate of the individuals with ability $y$ when the financial incentives to work amount to $Z$.

In this context, the set of agents of ability $y$ is overtaxed at financial incentives to work $Z(y)$ if there is some $Z>Z(y)$ such that $\left[Y^{*}(y)-Z\right] H[y, Z] \geq\left[Y^{*}(y)-Z(y)\right] H[y, Z(y)]$. If agents of ability $y$ are overtaxed at $Z(y)$, the state can provide them a higher level of utility, equal to $\max [v(Z+\rho), v(z+\rho)]$, with at least the same income $\left[Y^{*}(y)-Z\right] H[y, Z]$. Accordingly, overtaxation cannot be optimal. More precisely, Laroque (2005, theorem 3) has shown that feasible financial incentives to work $Z(y)$, such that $Z(y) \leq Y^{*}(y),{ }^{7}$ support a second-best

\footnotetext{
${ }^{6}$ Using equations (5), (9) and (10), the free entry condition $J(w, y)=0$ implies that taxes levied on an employed worker of ability $y$ are equal to $\tau(y)=Y^{*}(y)-w(y)$. When active individuals are perfectly insured, equations (7) and (9) imply that $Z(y)=w(y)-\rho$. Therefore, one gets $\tau(y)=Y^{*}(y)-Z(y)-\rho$. Moreover, every inactive individual costs $\rho$.

${ }^{7}$ Following Laroque, we restrict the analysis of necessary and sufficient conditions to tax-subsidy schemes
} 
allocation if and only if no category of ability $y$ is overtaxed at $Z(y)$. Let us denote by $\tilde{Z}(y)$ any function ${ }^{8}$ that belongs to the set of second-best financial incentives to work and such that $\tilde{Z}(y) \leq Y^{*}(y)$. Then, the properties of the optimal tax-subsidy schemes are summarized in the following proposition.

Proposition 3 When Assumptions 1 and 2 are satisfied, a feasible tax-subsidy scheme $\{\tau(w), f(w), b($ such that $\tau(w)+\rho \geq 0$ is optimal if and only if:

1. $b(w)=w$

2. $f(w)=b(w)+\tau(w)$

3. The payroll tax schedule $\tau(w)$ is defined by:

$$
\tau(w)=Y^{*}\left[\tilde{Z}^{-1}(w-\rho)\right]-w \quad \text { with } \quad \rho=\int_{y_{\min }}^{+\infty}\left[Y^{*}(y)-\tilde{Z}(y)\right] H[y, \tilde{Z}(y)] d y
$$

\section{Proof. see appendix B.}

This proposition shows that second-best optimal policies necessarily include layoff taxes. More precisely, its condition 2. states that the optimal tax-subsidy schemes comprise layoff taxes that cover the social cost of job destructions, which amounts to the sum of the unemployment benefits and the payroll tax. In other words, the social cost of job destructions is equal to the loss imposed to the state, which comprises the unemployment benefits, $b(w)$, that are obtained by the unemployed worker, but not by the employee, plus the payroll tax, $\tau(w)$, that is payed when the job is filled, but not any more when it is destroyed.

such that $Z(y) \leq Y^{*}(y)$. Looking at more general tax-subsidy schemes is interesting but is not central to our analysis. Since $\tau(y)=Y^{*}(y)-Z(y)-\rho$ and $\rho \geq 0$, the assumption $Z(y) \leq Y^{*}(y)$ is equivalent to $\tau(y)+\rho \geq 0$. This condition simply states that net taxes payed by active individuals have to be positive. Net taxes are equal to the taxes levied on the production of the employees, $\tau(y)(1-q(y))+q(y) f(y)$, minus unemployment benefits, $q(y) b(y)$, plus the income guarantee $\rho$. Using the condition $f(w(y))=b(w(y))+\tau(w(y))$ one gets $\tau(y)(1-q(y))+q(y) f(y)-q(y) b(y)+\rho=\tau(y)+\rho$.

${ }^{8}$ It should be noticed that $Z(y)$ is necessarily increasing as equations (7) and (9) imply that $Z(y)=w(y)-\rho$, where $w(y)$ is an increasing function according to Proposition 2. 
From this point of view, it is worth stressing that the social cost of job destruction only amounts to the unemployment benefits when the aim of the state is to provide insurance to active individuals without cross-subsidization among individuals with different types $s$. This case is characterized by the following Corollary:

Corollary 1 The single first-best allocation attainable through the market allocation is implemented by the following tax-subsidy scheme:

$$
f(w)=b(w)=w, \rho=\tau(w)=0
$$

The allocation is characterized by:

$$
c(s)=\left\{\begin{array}{l}
Y^{*}(y) \text { if } z \leq Y^{*}(y) \\
0 \text { otherwise }
\end{array}, \quad \ell(s)=\left\{\begin{array}{l}
0 \text { if } z \leq Y^{*}(y) \\
1 \text { otherwise }
\end{array}\right.\right.
$$

Proof. Condition 1 of Proposition 1 is satistied if $b(w)=w$. Equations (2) and (4) imply that condition 2 of Proposition 1 is satisfied if $f(w)=b(w)$ and $\tau(w)=0$. According to condition 3 of Proposition 1, a first-best allocation requires that $Z(y)=Y^{*}(y)$. According to equation (7), one gets $Z(y)=w(y)=b(w(y))$ if $\rho=0$ and $b(w)=w$. Then, equations (5) and (6) imply that $Z(y)=Y^{*}(y)$ if $Z(y)=w(y)=b(w(y))=f(w(y))$ and $\tau(w)=0$.

Corollary 1 indicates that, in the first-best, unemployment benefits should not be financed by income taxes because there is no cross-subsidization across different types- $s$ individuals. Unemployment benefits should be financed by layoff taxes only. When there is no cross-subsidization among individuals with different types $s$, every type- $(y, z)$ individual gets the amount of marketable good that corresponds to his expected production, $Y^{*}(y)$, when he participates in the labor market and zero otherwise. In other words, the financial incentives to work take their maximum value: $Z(y)=Y^{*}(y)$. This implies that the decentralized equilibrium yields a first-best allocation.

Corollary 1 generalizes the result of Blanchard and Tirole (2004) - obtained in a framework with a single type $s$ - according to which efficiency requires that layoff taxes be equal to un- 
employment benefits. Our approach, that takes into account the heterogeneity of individuals in the tradition of Mirrlees (1971), allows us to analyze how layoff taxes should be integrated in optimal tax-subsidy schemes when there is redistribution of income across individuals with different types in the presence of endogenous job destruction.

From this point of view, it is worth noting that Proposition 3 implies that the layoff tax is necessarily larger than unemployment benefits for at least some type- $(y, z)$ workers, because positive $\tau(w(y))$ are needed for at least some type- $(y, z)$ when there is a positive income guarantee $\rho$ or redistribution of income across individuals with different types. It is the presence of payroll taxes that distorts the participation decisions. The negative impact of income taxation on labor supply is at the basis of the problem tackled by the research on optimal taxation $a$ $l a$ Mirrlees (1971) and Diamond (1980) in which the state faces a trade-off between the degree of redistribution of income and the degree of participation in the labor force. When job destruction decisions are taken into account, layoff taxes belong very naturally to any optimal tax-subsidy scheme. In other words, layoff taxes are not only useful to finance unemployment benefits, as it is usually acknowledged, they are also useful to induce individuals to internalize the impact of their job destructions decisions on the budget of the state when there is income redistribution across individuals with different abilities $y$ and different tastes for lesure.

It has just been claimed that layoff taxes should be integrated in optimal tax-subsidy schemes. However, most actual tax schemes ${ }^{9}$ do not comprise layoff taxes. So, the question that naturally arises is: what is the loss induced by the absence of layoff taxes in actual tax schemes? In other words, what supplementary public budget can we raise by introducing layoff taxes in a tax-subsidy scheme without layoff tax? A related issue is the optimal level of the layoff tax. Unfortunately, our static model is of little help to address such issues. It only indicates that the

\footnotetext{
${ }^{9}$ There are some exceptions, such as the Contribution Delalande in France for instance, according to which employers must pay layoff taxes to fire workers who are more than 50 years old. The aim of this tax is to induce the employers to take into account the social cost of the layoff of senior workers whose probability to find a job once fired is very small in France.
} 
layoff tax should be equal to the social cost of job destructions, which amounts to the sum of the payroll tax and the unemployment benefits in a static framework. However, the social cost is obviously related to unemployment and job durations. From this point of view, a dynamic model, that accounts for labor market flows, is essential to evaluate the quantitative impact of layoff taxes.

\section{A dynamic version of the benchmark model}

The economy is basically the same as in the benchmark model except that time is continuous and individuals live forever.

An individual is still described by a pair of constant exogenous characteristics $s=(y, z)$ where $y$ stands for his ability and $z$ for his taste for leisure. We assume that $(y, z)$ has joint density $h(y, z)$ with $h>0$ over the support $S \subset\left[y_{\min },+\infty\right) \times \mathbb{R} ; h$ is continuous. The preferences of the type- $s$ individuals are represented by the discount rate $r>0$ and the instantaneous utility function $v(c+z \ell)$, twice differentiable, increasing and strictly concave, where $c \geq 0$ denotes instantaneous consumption, $\ell \in\{0,1\}$ denotes instantaneous leisure that amounts to zero if the individual is active (either employed or unemployed) and to one if he is not in the labor force.

Individuals who look for a job get offers at an exogenous Poisson rate $\lambda$. Once a worker has gotten an offer, he can immediately start to produce. Creating a job for a type- $(y, z)$ individual entails a fixed cost denoted by $k(y)>0$.

A starting job occupied by an individual with ability $y$ produces $x_{U} \cdot y$ units of the marketable good per unit of time, where $x_{U}$ is the upper bound of the time invariant cumulative distribution ${ }^{10} G($.$) . Occupied jobs face idiosyncratic productivity shocks with constant arrival$ rate $\mu$. When a productivity shock occurs, a new value of the idiosyncratic productivity, denoted by $x$, is drawn from the distribution $G($.$) , and the productivity of the job amounts to x \cdot y$. In

\footnotetext{
${ }^{10}$ The assumption that all jobs start at at the maximum possible production is familiar in matching models with endogenous job destructions (see Mortensen and Pissarides, 1994). This assumption simplifies the model without substantialy changing the results that could be achieved with other, perhaps more realistic, assumptions.
} 
this context, it turns out that jobs are destroyed if $x$ is below a reservation value, denoted by $X(y)$.

An allocation defines, for each date $t \geq 0$, the consumption and the employment status of all the agents of the economy. Namely, it is a mapping that associates to each type- $s$ individual, conditional on the realization of productivity $x$ for active individuals, his consumption and his employment status at every date. All allocations have to be feasible, i.e. the overall consumption of the marketable good cannot exceed the global resources at the disposal of the social planner. For the sake of simplicity, we consider the case of a "small open economy" within which the state can borrow and lend on a perfect market at an exogenous interest rate denoted by $r$. This assumption allows us to focus only on stationary allocations.

\subsection{First-best allocations}

Let us begin to analyze the case in which the allocation is chosen by a social planner who has the same information set as in the first-best case of the static model - see $\S 2.2$ ) -, which means that the planner has complete information on the pair $s=(y, z)$ describing each agent's characteristics. As in the static environment, first-best allocations are such that there are no other feasible allocations that can improve the welfare of at least one agent without worsening the welfare of the others. It is assumed that feasible allocations are ranked according to the expected utility criterion conditional on characteristics $(y, z)$, but not on the employment status of type- $(y, z)$ individuals at date $t=0$.

The planner chooses an allocation at date $t=0$. At this date, the state of the economy is described by the function $l_{0}(y) \geq 0$ that defines the number of jobs occupied by individuals with ability $y$. For the sake of simplicity, we consider initial conditions in which only individuals belonging to the (first-best) set $S_{A}$ of active individuals may be employed at date $t=0 .{ }^{11}$ The

\footnotetext{
${ }^{11}$ Looking at initial conditions in which the social planner destroys jobs at $t=0$ because some employees belong to the (first-best) set of inactive individuals at $t=0$ would complicate the presentation without adding any interesting insight for our purpose.
} 
time sequence of events runs as follows:

1) At date $t=0$, the social planner announces the consumption of the marketable good of every type- $s$ individuals, conditional on the productivity $x$ for active individuals, that will prevail at every date $t \geq 0$. The social planner decides which set of agents $s \in S_{I}$ will be inactive $(\ell(s)=1)$, and which set of agents $s \in S_{A}$ will be allowed to search for a job $(\ell(s)=0)$ at every date $t \geq 0$. The social planner also announces which filled jobs will be destroyed once hit by a productivity shock at every date $t>0$.

2) At any date $t \geq 0$, the individuals participate in the labor market, produce and consume according to the plan announced at $t=0$.

The properties of the first-best allocations are derived in appendix C.1. They are summarized in the following Proposition:

Proposition 4 A feasible stationary allocation is a first-best allocation if and only if:

1. Filled jobs whose productivity is below the reservation value $X^{*}(y)$ defined by

$$
X^{*}(y)=\frac{\lambda\left[x_{U} y-(r+\mu) k(y)\right]-\mu y \int_{X^{*}(y)}^{x_{U}} x d G(x)}{y\left[\lambda+r+\mu G\left(X^{*}(y)\right)\right]}
$$

are destroyed.

2. Every individual with the same type $s$ belonging to the set $S_{A}$ of active individuals gets the same consumption level whether employed of unemployed.

3. The set $S_{A}$ of active individuals comprises all the type-s individuals whose taste for leisure $z$ is below the expected production flow of a job seeker, $Y_{U}^{*}(y)$, defined by:

$$
r Y_{U}^{*}(y)=\frac{\lambda\left[x_{U}-X^{*}(y)\right]-(r+\mu) k(y)}{r+\mu}
$$

and the set $S_{I}$ of inactive individuals comprises all the agents such that $z>r Y_{U}^{*}(y)$. 
Proposition 4 shows that the first-best allocations of the dynamic model look like those of the static model (described in Proposition 1). First, all jobs whose discounted expected production is below the value of the discounted expected production of a job seeker are destroyed. Second, it is always optimal to insure individuals. Accordingly, consumption is conditional on the type- $s$ of individuals, but does not hinge on the realization of productivity shocks. Third, type- $(y, z)$ individuals participate in the labor market only and only if their taste for leisure $z$ is smaller than $r Y_{U}^{*}(y)$, which is their discounted expected production flow in unemployment.

However, it is worth noting that, contrary to the static case, employment is not constant over time. At $t=0$, there are $l_{0}(y)$ job filled by individuals with productivity $y$, and the law of motion of the number of jobs filled by individuals with productivity $y$, denoted by $l(y)$, is defined by

$$
i(y)=\lambda\left[H\left(y, r Y_{U}^{*}(y)\right)-l(y)\right]-\mu G\left(X^{*}(y)\right) l(y),
$$

where $H\left(y, r Y_{U}^{*}(y)\right)=\int_{-\infty}^{r Y_{U}^{*}(y)} h(y, z) d z$ denotes the first-best labor force participation rate of individuals with ability $y$.

\subsection{Second-best allocations}

Let us now consider the design of optimal fiscal policies in a second-best environment in which the state does not observe the characteristics of the agents, as in section 3 .

The state is committed, at date $t=0$, to a time invariant tax-subsidy scheme $\{\tau(w), f(w), b(w), \rho\}$. Individuals evolve in a decentralized economy in which firms enter into Bertrand competition to hire workers. Namely, it is assumed that when a job seeker has met a firm, the information is instantly known to other firms that can make job offers. We shall use the same Pareto criterion to define the optimal policies as in the static environment of section 3. By definition, a tax-subsidy scheme is optimal if it is feasible and if there is no other feasible tax-subsidy scheme that can improve the welfare of at least one agent without worsening the welfare of the others. In other words, optimal tax-subsidy schemes implement second-best allocations. Like in the 
first-best, it is assumed that feasible allocations are ranked according to the expected utility criterion conditional on characteristics $(y, z)$, but not on the employment status of type- $(y, z)$ individuals at date $t=0$.

At $t=0$, the state of the economy is described by the function $l_{0}(y) \geq 0$ that defines the number of filled jobs for every productivity level $y$. As in the first-best, we consider initial conditions in which only individuals belonging to the (second-best) set $S_{A}$ of active individuals may be employed at date $t=0$. The time sequence of events runs as follows:

1) At date $t=0$, the state chooses a time invariant tax-subsidy scheme $\{\tau(w), f(w), b(w), \rho\}$.

2) At dates $t>0$,

- individuals decide whether they search for a job or stay inactive. ${ }^{12}$

- employers enter into Bertrand competition to hire workers.

- the idiosyncratic productivity shocks $x$ occur and employers decide whether they keep the workers or they destroy the jobs. Then, employers pay the wage and the payroll tax for every continuing job. Every destroyed job gives rise to the payment of layoff taxes. Employed workers get a wage $w$, unemployed workers get unemployment benefits $b(w)$ and inactive individuals get the garantee income $\rho$.

Then, like in the static case, we focus on stationary tax-subsidy scheme $\{\tau(w), f(w), b(w), \rho\}$ that satisfy some properties. These properties, which replicate Assumptions 1 and 2 in a dynamic framework, are presented in Assumptions A1 and 12 in Appendix C.2. Once the state has announced a stationary tax-subsidy scheme $\{\tau(w), f(w), b(w), \rho\}$ that satisfies these properties, there exists a unique stationary equilibrium value of the wage $w(y)$, the financial incentives to work $Z(y)$ and the reservation productivity $X(y)$. These three variables, which are forward looking, jump on their stationary value at $t=0$. Therefore, the number of individuals with

\footnotetext{
${ }^{12}$ This step differs from the static case, because it takes time to search for a job. Hence, knowing the tax-subsidy scheme, the workers must first decide if they engage in searching for a job. Notwithstanding, alike the static case, it is assumed that individuals who decide to belong to the labor force reveal their true productivity (see foonote $2)$.
} 
ability $y$ who participate in the labor market, denoted by $n(y)=\int_{-\infty}^{Z(y)} h(y, z) d z$, also jumps on its stationary equilibrium value at $t=0$. The same holds true for the job destruction rate $\mu G(X(y))$. In this framework, employment of workers with ability $y$, denoted by $l(y)$, is a predetermined variable whose dynamics is defined by the equation

$$
\dot{l}(y)=\lambda[n(y)-l(y)]-q(y) l(y)
$$

and by the initial value of $l(y)$ at date $t=0$, denoted by $l_{0}(y)$.

The properties of the optimal tax-subsidy schemes are characterized for any second-best financial incentives to work $\tilde{Z}(y)$ such that $\tilde{Z}(y) \leq r Y_{U}^{*}(y)$, where $Y_{U}^{*}(y)$ denotes the present value of the discounted life time production of an unemployed worker ${ }^{13}$. These properties, analyzed in details in appendix C.2, are closely related to those highlighted in the static model: there is perfect insurance against unemployment risk and layoff taxes are needed to obtain efficient job destructions. These properties are summarized in the following proposition:

Proposition 5 When Assumptions A1 and A2 are satisfied, a feasible tax-subsidy scheme $\{\tau(w), f(w), b(w), \rho\}$ such that $\tau(w)+\rho \geq r[b(w)-\rho] / \lambda$ is optimal if and only if:

$$
\text { 1. } b(w)=w
$$

$$
\text { 2. }(r+\lambda) f(w)=b(w)+\tau(w), f^{\prime}(w)>0
$$

\footnotetext{
${ }^{13}$ Like in the static model, we restrict the analysis of necessary and sufficient conditions to tax-subsidy schemes such that $\tilde{Z}(y) \leq r Y_{U}^{*}(y)$ which is equivalent to restrict the analysis to the cases in which net taxes payed by active individuals are positive. It is shown, in Appendix C.2, equation (C24), that the discounted value of taxes, minus unemployment benefits, payed by an individual with abililty $y$ who enters into the labor force, denoted by $B_{U}(y)$, solves

$$
r B_{U}(y)=-\frac{r+q(y)}{r+\lambda+q(y)} b(y)+\frac{\lambda}{r+\lambda+q(y)}[\tau(y)+q f(y)] .
$$

Discounted net taxes payed by an individual with ability $y$ who enters into the labor market are equal to $B_{U}(y)$ plus the discounted value of the income guarantee, $\rho / r$. Using the condition $(r+\lambda) f(w(y))=b(w(y))+\tau(w(y))$, it is easy to check that $B_{U}(y)+(\rho / r) \geq 0$ is equivalent to $\tau(w)+\rho \geq r[b(w)-\rho] / \lambda$.
} 
3. The payroll tax schedule $\tau(w)$ is defined by:

$$
\begin{aligned}
& \tau(w)=\frac{r+\lambda}{\lambda} r Y_{U}^{*}\left[\tilde{Z}^{-1}(w-\rho)\right]-w \\
& \text { with } \quad \rho=\int_{y_{\min }}^{+\infty}\left[r Y_{U}^{*}(y) \frac{\left[n(y)-l_{0}(y)\right] \lambda+r l_{0}(y)}{\lambda}-\tilde{Z}(y) n(y)\right] d y
\end{aligned}
$$

Proposition 5 allows us to shed some light on the interpretation of the social cost of job destruction in a dynamic context. According to claim 2., it turns out that the social cost of job destruction amounts to the discounted value of the loss borne by the state. During the spell in which the worker who has been fired is unemployed, the state losses the unemployment benefits and the tax that the worker would pay if he was employed. As the exit rate from unemployment is $\lambda$, the discounted cost of the destruction of a job with a wage $w$, denoted by $C(w)$, satisfies the Bellman equation

$$
r C(w)=b(w)+\tau(w)-\lambda C(w)
$$

which yields a value of the social cost of job destruction equal to the layoff tax defined in Proposition 5.

\section{Quantitative analysis}

The quantitative analysis aims at analyzing the potential loss entailed by tax-subsidy schemes that do not utilize layoff taxes.

\subsection{The benchmark calibration}

The values of the parameters are chosen to represent the main features of a typical Continental European economy with high level of redistribution of income and high unemployment rate. Laroque (2005) suggests that the French economy is close to the Laffer bound, which corresponds to the tax schedule that maximizes the income guarantee. Accordingly, our benchmark calibration assumes that the economy is on its Laffer bound and that there are payroll taxes but no layoff taxes. Then the impact of the introduction of layoff taxes is analyzed. 
The annual discount rate, $r$, is equal to 0.05 . The abilities, $y$, and the tastes for leisure, $z$, have independent Log Normal Distributions. The distribution of the idiosyncratic productivity shocks, $x$, is uniform over the interval $\left[x_{\text {inf }}, x_{U}\right]$. The upper bound of the idiosyncratic productivity shocks, $x_{U}$, is normalized to 1 . The job creation cost is a linear function of the ability: $k(y)=c \cdot y$. The value of the hiring cost parameter $c$ is set to 0.15 in line with the calibrations of Mortensen and Pissarides (1999, p. 2605) based on empirical evidence. When $f(w)=0$ and $k(y)=c \cdot y$, the threshold value $X(y)$ below which jobs are destroyed does not depend on the ability (see equation (C16) in appendix B) and can be denoted $X$. Thus the flows equilibrium on the labor market reads $\lambda u=\mu G(X)(1-u)$, where $u$ stands for the aggregate unemployment rate.

The average unemployment spell is assumed to be equal to one year $(\lambda=1)$ and the aggregate unemployment rate $u$ amounts to 10 percent. Thus the flows equilibrium on the labor market implies that the annual job destruction rate $\mu G(X)$ amounts to 11.11 percent. From an empirical perspective, there is no way to distinguish the arrival rate of shocks $\mu$ from the reservation productivity $X$ and thus from the lower bound of the productivity $x_{\mathrm{inf}}$. In the benchmark calibration, it is assumed that $x_{\mathrm{inf}}=0.5$ which implies that $\mu=0.117^{14}$

Then, the properties of the distributions of the abilities and the taste for leisure have been set to reach an aggregate employment rate of 60 percent. Namely, the mean and standard deviation of $z$ are normalized to zero and 1 respectively. The lower bound of $z$ is equal to -1 . The lower bound of $y$ is zero and its standard deviation is also equal to 1 . The average of $y$ has been set to 1.977 in order to get an employment rate of 60 percent.

Table 1 shows the consequence of the introduction of layoff taxes on the stationary values

\footnotetext{
${ }^{14}$ With $f(w)=0$ and $k(y)=c \cdot y$, equation (C16) in appendix C.2 gives $X=x_{U}-c(r+\mu)$. The distribution of the idiosyncratic shocks, $x$, being uniform over the interval $\left[x_{\text {inf }}, x_{U}\right]$, the job destruction rate reads $\mu G(X)=\mu \frac{X-x_{\text {inf }}}{x_{U}-x_{\text {inf }}}$, which implies that the relation between $x_{\text {inf }}$ and $\mu$ is defined by:

$$
\mu \frac{x_{U}-c(r+\mu)-x_{\mathrm{inf}}}{1-x_{\mathrm{inf}}}=\mu G(X)
$$

Setting $\mu G(X)=0.111, x_{U}=1, r=0.05, c=0.15$, and $x_{\mathrm{inf}}=0.5$ in this latter equation yields $\mu=0.117$.
} 


\begin{tabular}{lccc}
\hline \hline & Without layoff tax & With layoff tax & Difference \\
\hline Job destruction rate (\%) & 11.11 & 7.78 & $-29.27 \%$ \\
Unemployment rate (\%) & 10.0 & 7.21 & $-29 \%$ \\
Employment rate (\%) & 60.00 & 62.07 & $+3.45 \%$ \\
Output & 24.30 & 24.77 & $+1.93 \%$ \\
Income guarantee & 1.18 & 1.20 & $+1.64 \%$ \\
\hline
\end{tabular}

Table 1: The performance of the benchmark economy with layoff tax and without layoff tax.

of the job destruction rate, the unemployment rate, the employment rate, the output level and the income guarantee. ${ }^{15}$ The first column yields the value of these variables in the benchmark Rawlsian ${ }^{16}$ economy without layoff taxes. Then, the second column displays the stationary values of the same variables when the state introduces an optimal layoff tax schedule (i.e. satisfying Proposition 5) in such an economy.

It turns out that layoff taxes reduce unemployment, increase the employment rate, increase ouput and allows the state to increase the income guarantee. There is a strong drop in the job destruction rate and in the unemployment rate (around 29 percent for each). The employment rate increases for two reasons: the drop in the unemployment rate and the slight increase $(+0.34$ percent $)$ in the participation rate. The increase in output is smaller than the increase in employment because the introduction of layoff taxes induces firms to keep jobs with lower productivity.

In order to look at welfare issues, we analyze the consequences of the introduction of layoff taxes on the consumption index $c+z \ell$ of all type- $(y, z)$ of individuals. Inactive individuals, with $z>Z(y)$, get a consumption index equal to $z+\rho$ and active individuals, with $z \leq Z(y)$, get $w(y)=Z(y)+\rho$. Figure 1 displays the relative consumption gains $\frac{(c+z \ell) *(c+z \ell)}{c+z \ell}$ resulting from the introduction of layoff taxes where $(c+z \ell)^{*}$ denotes the value of the consumption index in the economy with layoff taxes and $(c+z \ell)$ stands for the consumption index in the economy without layoff taxes. It can be seen that all individuals are strictly better-off in the economy

\footnotetext{
${ }^{15}$ We compare steady states. Details are given in Appendix C.3.

${ }^{16}$ An economy that reaches its Laffer bound is called 'Rawlsian' because the income guarantee is maximized.
} 


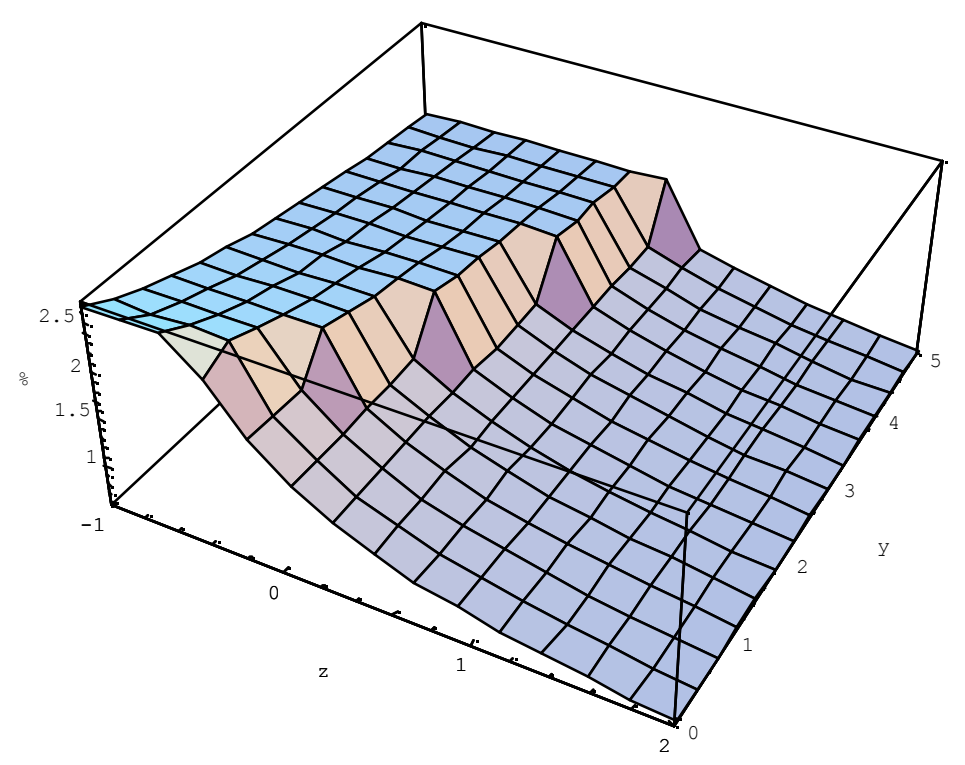

Figure 1: Consumption gains (in \%) resulting from the introduction of layoff taxes in the Rawlsian economy.

with layoff taxes than in the economy without layoff taxes. The maximal increase (measured in percentages) in the consumption index is equal to 2.65 percent. The relative increase in the consumption index is larger for the individuals with low productivity. It is also larger for the individuals who participate in the labor market (because their wage increases more than the garantee income) than for those who are inactive.

\subsection{Robustness checks}

The quantitative impact of layoff taxes on aggregate output, employment and welfare is closely related to the job destruction and creation process. From this point of view, the arrival rate of job offers, $\lambda$, and the arrival rate of productivity shocks, $\mu$, turn out to have a strong influence on the quantitative impact of layoff taxes. This issue is illustrated in Tables 2 and 3 where different values of the arrival rates of job offers and productivity shocks are considered. All the other parameters remain unchanged.

Table 2 displays the magnitude of the change in output, employment and income guarantee 


\begin{tabular}{ccccc}
\hline \hline$\lambda$ & Emp rate & $\Delta$ Output $(\%)$ & $\Delta \operatorname{Emp}(\%)$ & $\Delta$ Income guarantee $(\%)$ \\
\hline 1 (benchmark) & 60.00 & 1.93 & 3.45 & 1.64 \\
2 & 63.88 & 0.52 & 0.94 & 0.45 \\
3 & 65.27 & 0.23 & 0.44 & 0.21 \\
\hline
\end{tabular}

Table 2: Robustness checks: changes in output, employment rate and guarantee income induced by the introduction of layoff taxes for different values of the arrival rate of job offers.

when optimal layoff taxes are introduced for different values of the arrival rate of job offers. As we have considered a low value of the arrival rate of job offers in the benchmark economy, corresponding to a typical Continental European country with long unemployment spells, we look at higher values of $\lambda$. As all the other parameters remain unchanged, the higher value of the arrival rate of job offers changes the employment rate, whose value is given in the first column of Table 2. Table 2 shows that the gains induced by the introduction of layoff taxes decrease with the arrival rate of job offers. It is because the social cost of job destruction (defined in equation (13)) increases with the length of the unemployment spell. Accordingly, the introduction of layoff taxes yields higher returns in economies where the duration of unemployment is longer.

Table 3 shows what happens with different values of the arrival rate of productivity shocks. Let us recall that the job destruction rate amounts to 11.11 percent in the benchmark, which is a relatively low value. Therefore, we look at higher values of the arrival rate of productivity shocks. These higher values lead to lower employment rates whose values are given in the first column of Table 3.

It appears that the gains induced by the introduction of layoff taxes get larger when the arrival rate of productivity shocks is raised. As unemployment increases with this parameter, these results also suggest that layoff taxes become more efficient in economies where unemployment is high. 


\begin{tabular}{llccc}
\hline \hline \multicolumn{1}{c}{$\mu$} & Emp rate & $\Delta$ Output $(\%)$ & $\Delta \operatorname{Emp~}(\%)$ & $\Delta$ Income guarantee $(\%)$ \\
\hline 0.117 (benchmark) & 60.00 & 1.93 & 3.45 & 1.64 \\
0.15 & 58.02 & 2.84 & 5.11 & 2.40 \\
0.20 & 55.32 & 4.48 & 8.17 & 3.75 \\
\hline
\end{tabular}

Table 3: Robustness checks: change in output employment rates and income guarantee induced by the introduction of layoff taxes for different values of the arrival rate of productivity shocks.

\section{Conclusion}

This paper shows that optimal tax-subsidy schemes should comprise layoff taxes. It turns out that optimal layoff taxes are linked to the intensity of the redistribution of income: the optimal layoff tax is equal to the social cost of job destruction, which amounts to the discounted value of the unemployment benefits paid to the fired worker plus the payroll taxes (used to redistribute income across individuals with different abilities or different tastes for leisure) that the state losses when the job is destroyed. Accordingly, layoff taxes should represent a larger share of the wage when there are higher payroll taxes due to a more intensive redistribution of income.

Moreover, quantitative exercises suggest that the absence of layoff taxes found in most actual tax-subsidy schemes can give rise to significant welfare losses. Our benchmark simulation indicates that the introduction of layoff taxes may increase the employment rate by 3.5 percent and increase GDP by 2 percent in economies in which the redistribution of income is close to the Laffer bound.

Although we think that our result according to which optimal tax-subsidy schemes should comprise layoff taxes is general and relevant, our analysis needs to be further developed in some directions. First, our framework takes into account only some externalities induced by job destruction decisions. Actually, search and matching models stress that job destructions induce search externalities which imply that the decentralized equilibrium does not yield enough job destructions (Aghion and Howitt, 1998, Mortensen and Pissarides, 1999). From this perspective, it would be worth introducing negative layoff taxes (Cahuc and Zylberberg, 2004, chapter 10). 
We need to know more on the interactions between externalities and on their relative magnitude to know the optimal level of layoff taxes. Second, our framework assumes a very simple form of labor contracts, without ex-post bargaining that gives rise to hold-up problems. Moral hazard linked to unemployment insurance has also been neglected. Such issues, which have been explored by Blanchard and Tirole (2004) in a static framework without heterogenous individuals, are worth studying. Third, our assumption of an exogenous arrival rate of job offers does not allow us to account for the reaction of job creation to changes in the tax-subsidy schemes. These developments are on our research agenda. 


\section{References}

Abowd, J.and Kramarz, F. (2003), "The Costs of Hiring and Separations", Labour Economics, 10(5), pp. 499-530.

Aghion, P. and Howitt, P. (1998), Endogenous Growth Theory, Cambridge, Mass: Harvard University Press.

Anderson P. and Meyer B. (1993), "Unemployment Insurance in the United States: Layoff Incentives and Cross Subsidies", Journal of Labor Economics, 11(2), pp. 70-95.

Anderson P. and Meyer B. (2000), "The Effects of the Unemployment Insurance Payroll Tax on Wages, Employment, Claims and Denials", Journal of Public Economics, 78, pp. 81-106.

Azariadis, C. (1975), "Implicit contract and underemployment equilibria", Journal of Political Economy, 83(6), pp. 1183-1202.

Baily, M. (1974), "Wages and employment under uncertain demand", Review of Economic Studies, 41(1), pp. 37-50.

Beaudry, P. and Blackorby, C. (1997), "Taxes and Employment Subsidies in Optimal Redistribution Programs," Discussion Paper 22, University of British Columbia.

Blanchard, O. and Tirole, J. (2004), "The Optimal Design of Labor Market Institutions. A First Pass", NBER working paper 10443.

Burdett, K. and Wright, R. (1989a), "Unemployment Insurance and Short-Time Compensation: The Effects on Layoffs, Hours per Worker and Wages", Journal of Political Economy, 97, pp. 1479-1496. 
Burdett, K. and Wright, R. (1989b), "Optimal Firm Size, Taxes, and Unemployment", Journal of Public Economics, 39, pp. 275-287.

Cahuc, P. and Malherbet, F. (2004), "Unemployment Compensation Finance and Labor Market Rigidity", Journal of Public Economics, 88, pp. 481-501.

Cahuc, P. and Zylberberg, A. (2004), Labor Economics, Cambridge, Mass: MIT Press.

Choné, P. and Laroque, G. (2005): "Optimal Incentives for Labor Force Participation," Journal of Public Economics, 89, pp. 395-425.

Chui, H. and Karni, E. (1998), "Endogenous Adverse Selection and Unemployment Insurance", Journal of Political Economy, 106, pp. 806-827.

Diamond, P. (1980), "Income Taxation with Fixed Hours of Work," Journal of Public Economics, 13, pp. 101-110.

Feldstein M. (1976), "Temporary Layoffs in the Theory of Unemployment", Journal of Political Economy, 84, pp. 937-957.

Hopenhayn, H. and Nicolini, J., (1997), "Optimal Unemployment Insurance", Journal of Political Economy, 105, pp. 412-438.

Laroque, G. (2005), "Income Maintenance and Labor Force Participation”, Econometrica, 73, pp. 341-73.

Ljungqvist, L. and Sargent, T. (2000), Recursive Macroeconomic Theory, Cambridge, Mass: MIT Press.

Mirrlees, J. (1971), "An Exploration in the Theory of Optimum Income Taxation," Review of Economic Studies, 38, pp. 175-208. 
Pissarides, C. (2001), "Employment Protection", Labour Economics, vol 8, 131-159.

Mortensen, D. and Pissarides, C. (1999), "New Developments in Models of Search in the Labor Market", in Ashenfelter, O. and Card, D. (eds), Handbook of Labor Economics, Elsevier Science Publisher, vol 3B, chapter 39.

Rosen, S. (1985), "Implicit Contracts: A Survey", Journal of Economic Literature, vol 23, pp. $1144-1175$.

Saez, E. (2002), "Optimal Income Transfer Programs: Intensive versus Extensive Labor Supply Responses," Quarterly Journal of Economics, 117, pp. 1039-1073.

Salanié, B. (2003), The Economics of Taxation, MIT Press. 


\section{Appendix}

\section{A Proof of Proposition 1}

Necessary conditions have been shown in the text. It remains to be proved that any feasible allocation which satisfies conditions 1,2 and 3 is Pareto optimal. Let us show that an allocation that makes every agent as least as well off and some strictly better off than an allocation which satisfies conditions 1, 2 and 3 is not feasible.

The feasibility constraint for a first-best allocation which satisfies conditions 1, 2 and 3 and yields consumptions denoted by $c(y, z)$ reads

$$
\int_{S_{A}} Y^{*}(y) h(y, z) d y d z=\int_{S_{A}} c(y, z) h(y, z) d y d z+\int_{S_{I}} c(y, z) h(y, z) d y d z,
$$

where $Y^{*}(y)=y \int_{0}^{+\infty} x d G(x)-k(y)$ stands for the average first-best net production of employees with ability $y$.

Let us denote by $\hat{c}(y, z, x)$ the consumption of type- $(y, z)$ active individuals and by $\hat{c}(y, z)$ the consumption of type- $(y, z)$ inactive individuals for a feasible allocation (called henceforth the alternative allocation) that makes every individual at least as well off and some strictly better off than a firstbest allocation (called henceforth the initial allocation) which satisfies conditions 1 , 2 and 3 and yields consumptions denoted by $c(y, z)$.

The feasibility constraint for the alternative allocation reads

$$
\int_{S_{\hat{A}}} \hat{Y}(y) h(y, z) d y d z=\int_{S_{\hat{A}}}\left(\int_{\mathbb{R}} \hat{c}(y, z, x) d G(x)\right) h(y, z) d y d z+\int_{S_{\hat{I}}} \hat{c}(y, z) h(y, z) d y d z
$$

where $\hat{Y}(y)=y \int_{\hat{W}(y)} x d G(x)-k(y)$ stands for the average net production of employees with ability $y$ and $S_{\hat{A}}$, $S_{\hat{I}}$ denote the set of active and inactive individuals respectively.

Let us denote by $S_{A \hat{A}}$ the set of agents who are active in both allocations, by $S_{I \hat{I}}$ the set of those who are inactive in both allocations, by $S_{A \hat{I}}$ the set of those who are active for the initial allocation and inactive for the alternative allocation, by $S_{I \hat{A}}$ the set of those who are inactive for the initial allocation and active for the alternative allocation. By definition one gets:

$$
\begin{gathered}
\int_{S_{A \hat{A}}}\left(\int_{\mathbb{R}} \hat{c}(y, z, x) d G(x)\right) h(y, z) d y d z+\int_{S_{I \hat{I}}} \hat{c}(y, z) h(y, z) d y d z \geq \int_{S_{A \hat{A}} \cup S_{I \hat{I}}} c(y, z) h(y, z) d y d z \\
\int_{S_{A \hat{I}}}[\hat{c}(y, z)+z] h(y, z) d y d z \geq \int_{S_{A \hat{I}}} c(y, z) h(y, z) d y d z \\
\int_{S_{I A}}\left(\int_{\mathbb{R}} \hat{c}(y, z, x) d G(x)\right) h(y, z) d y d z \geq \int_{S_{I A}}[c(y, z)+z] h(y, z) d y d z
\end{gathered}
$$


with some strict inequality. Summing up the three previous equations yields

$$
\begin{gathered}
\int_{S_{A}}\left(\int_{\mathbb{R}} \hat{c}(y, z, x) d G(x)\right) h(y, z) d y d z+\int_{S_{I}} \hat{c}(y, z) h(y, z) d y d z> \\
\int_{S} c(y, z) h(y, z) d y d z+\int_{S_{I \hat{A}}} z h(y, z) d y d z-\int_{S_{A \hat{I}}} z h(y, z) d y d y
\end{gathered}
$$

From condition 3 it follows that

$$
\begin{aligned}
& \int_{S_{I \hat{A}}} z h(y, z) d y d z \geq \int_{S_{I \hat{A}}} Y^{*}(y) h(y, z) d y d z \\
& \int_{S_{A \hat{I}}} z h(y, z) d y d z \leq \int_{S_{A \hat{I}}} Y^{*}(y) h(y, z) d y d z .
\end{aligned}
$$

These two equations imply, together with (A1):

$$
\begin{aligned}
\int_{S_{\hat{A}}}\left(\int_{\mathbb{R}} \hat{c}(y, z, x) d G(x)\right) h(y, z) d y d z+\int_{S_{\hat{I}}} \hat{c}(y, z) h(y, z) d y d z> & \\
& \int_{S} c(y, z) h(y, z) d y d z+\int_{S_{I \hat{A}}} Y^{*}(y) h(y, z) d y d z-\int_{S_{A \hat{I}}} Y^{*}(y) h(y, z) d y d z
\end{aligned}
$$

As $c(y, z)$ is feasible, it satisfies

$$
\int_{S} c(y, z) h(y, z) d y d z=\int_{S_{A \mathcal{I}} \cup S_{A \mathcal{A}}} Y^{*}(y) h(y, z) d y d z
$$

which yields

$$
\begin{aligned}
& \int_{S_{A}}\left(\int_{\mathbb{R}} \hat{c}(y, z, x) d G(x)\right) h(y, z) d y d z+\int_{S_{\hat{I}}} \hat{c}(y, z) h(y, z) d y d z> \\
& \int_{S_{A \hat{I}} \cup S_{A \hat{A}}} Y^{*}(y) h(y, z) d y d z+\int_{S_{I \hat{A}}} Y^{*}(y) h(y, z) d y d z-\int_{S_{A \hat{I}}} Y^{*}(y) h(y, z) d y d z= \\
& \int_{S_{I A} \cup S_{A A}} Y^{*}(y) h(y, z) d y d z .
\end{aligned}
$$

As $S_{\hat{A}}=S_{A \hat{A}} \cup S_{A \hat{I}}$, one gets:

$$
\int_{S_{A}}\left(\int_{\mathbb{R}} \hat{c}(y, z, x) d G(x)\right) h(y, z) d y d z+\int_{S_{\hat{I}}} \hat{c}(y, z) h(y, z) d y d z>\int_{S_{A}} Y^{*}(y) h(y, z) d y d z .
$$

From the productive efficiency condition 1 one has $Y^{*}(y) \geq Y(y), \forall y$. This condition implies, together with the previous inequality:

$$
\int_{S_{\hat{A}}}\left(\int_{\mathbb{R}} \hat{c}(y, z, x) d G(x)\right) h(y, z) d y d z+\int_{S_{\hat{I}}} \hat{c}(y, z) h(y, z) d y d z>\int_{S_{\hat{A}}} Y(y) h(y, z) d y d z,
$$

which proves that the alternative allocation is not feasible. 


\section{B Proof of Proposition 3}

Let us first notice that when the state implements the tax-subsidy scheme $\{b(w), \tau(w), f(w), \rho\}$, the equilibrium wage is an increasing function of $y$ that is denoted by $w(y)$. The equilibrium values of the other variables can be denoted as $b(y)=b(w(y)), \tau(y)=\tau(w(y), f(y)=f(w(y)), X(y)=X(w(y), y)$, $q(y)=G(X(y))$ and $Z(y)=Z(w(y), y)$.

Proposition 3 is proved as follows. First, we define the optimal value of $\{w(y), b(y), X(y), \rho\}$ for any second-best financial incentives to work $\tilde{Z}(y) \leq Y^{*}(y)$. Then we find out how this solution can be implemented by the appropriate choice of $\{\tau(w), b(w), f(w), \rho\}$.

The budget constraint of the state reads

$$
\int_{y_{\min }}^{+\infty}\left(\int_{-\infty}^{Z(y)}\{[1-G(X(y))] \tau(y)+G(X(y))[f(y)-b(y)]\} h(y, z) d z\right) d y \geq \rho\left[1-\int_{y_{\min }}^{+\infty} H[y, Z(y)] d y\right],
$$

where $H[y, Z(y)]=\int_{-\infty}^{Z(y)} h(y, z) d z$. Using the free entry condition:

$$
\int_{X(y)}^{+\infty}[x \cdot y-w(y)-\tau(y)] d G(x)-G(X(y)) f(y)=k(y), \quad \forall y \geq y_{\min },
$$

the budget constraint of the state (B1) can be rewritten as:

$$
\int_{y_{\min }}^{+\infty}\{Y(y)-[1-G(X(y))] w(y)-G(X(y)) b(y)\} H[y, Z(y)] d y \geq \rho\left[1-\int_{y_{\min }}^{+\infty} H[y, Z(y)] d y\right]
$$

where $Y(y)=y \int_{X(y)}^{+\infty} x d G(x)-k(y)$.

Accordingly, the maximization problem which defines the optimal value of $\{w(y), b(y), X(y), \rho\}$ for any second-best financial incentives to work $\tilde{Z}(y) \leq Y^{*}(y)$ reads

$$
\max _{\{w(y), b(y), X(y), \rho\}} \rho
$$

subject to

$$
\begin{gathered}
v[\tilde{Z}(y)+\rho]=[1-G(X(y))] v(w(y))+G(X(y)) v(b(y)), \quad \forall y \geq y_{\min } \\
\int_{y_{\min }}^{+\infty}\{Y(y)-[1-G(X(y))] w(y)-G(X(y)) b(y)\} H[y, \tilde{Z}(y)] d y \geq \rho\left[1-\int_{y_{\min }}^{+\infty} H[y, \tilde{Z}(y)] d y\right] .
\end{gathered}
$$

Let us denote by $\lambda(y)$ and $\mu$ the Lagrange multipliers associated with constraints (B4) and (B5) respectively. The Lagrangian reads

$$
\begin{aligned}
\mathcal{L} & =\rho+\int_{y_{\min }}^{+\infty} \lambda(y)\{[1-G(X(y))] v(w(y))+G(X(y)) v(b(y))-v[\tilde{Z}(y)+\rho]\} d y+ \\
& \mu\left[\int_{y_{\min }}^{+\infty}\{Y(y)-[1-G(X(y))] w(y)-G(X(y)) b(y)\} H[y, \tilde{Z}(y)] d y-\rho\left[1-\int_{y_{\min }}^{+\infty} H[y, \tilde{Z}(y)] d y\right]\right]
\end{aligned}
$$


The first-order conditions can be written as

$$
\begin{gathered}
\frac{\partial \mathcal{L}}{\partial X(y)}=0 \Leftrightarrow \lambda(y)\left[v^{\prime}(b(y))-v^{\prime}(w(y))\right]=\mu(y X(y)-[w(y)-b(y)]) H[y, \tilde{Z}(y)], \quad \forall y \geq y_{\min }, \\
\frac{\partial \mathcal{L}}{\partial w(y)}=0 \Leftrightarrow \lambda(y) v^{\prime}(w(y))=\mu H[y, \tilde{Z}(y)], \quad \forall y \geq y_{\min } \\
\frac{\partial \mathcal{L}}{\partial b(y)}=0 \Leftrightarrow \lambda(y) v^{\prime}(b(y))=\mu H[y, \tilde{Z}(y)], \quad \forall y \geq y_{\min } \\
\frac{\partial \mathcal{L}}{\partial \rho}=0 \Leftrightarrow 1-\int_{y_{\text {min }}}^{+\infty} \lambda(y) v^{\prime}[\tilde{Z}(y)+\rho] d y=\mu\left[1-\int_{y_{\min }}^{+\infty} H[y, \tilde{Z}(y)] d y\right] .
\end{gathered}
$$

Equations (B7) and (B8) imply that $b(y)=w(y)=\tilde{Z}(y)+\rho, \forall y \geq y_{\min }$. As $w(y)=\tilde{Z}(y)+\rho$, equation (B7) reads $\lambda(y) v^{\prime}(\tilde{Z}(y)+\rho)=\mu H[y, \tilde{Z}(y)]$ which yields in (B9): $\mu=1$. Thus, equation (B7) implies that $\lambda(y)>0, \forall y \geq y_{\text {min }}$. Eventually, when $b(y)=w(y), \lambda(y)>0, \forall y \geq y_{\min }$ and $\mu>0$, equation (B6) implies that $X(y)=0$.

At this stage, it has been proved that the optimal value of $\{w(y), b(y), X(y), \rho\}$ satisfies $b(y)=w(y)$ and $X(y)=0$ for any second-best financial incentives to work $\tilde{Z}(y) \leq Y^{*}(y)$. Theses properties transform our model into a particular version of Laroque's (2005) model of labor supply decisions at the extensive margin with no unemployment. Our model is now such that a type- $(y, z)$ agent who decides to "work" produces $Y^{*}(y)$ and earns an income equal to $\tilde{Z}(y)+\rho$; if he decides to stay idle he produces nothing and earns $z+\rho$. Theorem 3 in Laroque (2005) completely characterizes the second-best optimal financial incentives to work $\tilde{Z}(y)$ in this case. It is shown that feasible financial incentives to work $\tilde{Z}(y)$, such that $\tilde{Z}(y) \leq Y^{*}(y)$, support a second-best allocation if and only if no category of ability $y$ is overtaxed at $\tilde{Z}(y)$.

The optimal value of $\rho$ can be obtained by substituting the values of $w(y)$ and $b(y)$ which are equal to $\tilde{Z}(y)+\rho$ into the - binding - constraint $(\mathrm{B} 5)$. One gets $\rho=\int_{y_{\min }^{+\infty}}^{+}\left[Y^{*}(y)-\tilde{Z}(y)\right] H[y, \tilde{Z}(y)] d y$. Let us find out how this solution can be implemented by the appropriate choice of $\{\tau(w), b(w), f(w), \rho\}$.

The equality $b(y)=w(y)$ is merely implemented by $b(w)=w$ which proves condition 1 . of Proposition 3.

The appropriate choice of $\tau(w)$ and $f(w)$ can be defined by noticing that there exists a bijection between $(\tau(y), f(y))$ and $(w(y), X(y))$ which is defined by two equations: namely the reservation productivity of the firms (equation (4))

$$
X(y)=\frac{w(y)+\tau(y)-f(y)}{y}, \quad \forall y \geq y_{\min },
$$

and the free entry condition (B2), which reads, using the definition of the reservation productivity of the firms (B10):

$$
f(y)=-k(y)+\int_{X(y)}^{+\infty}[x \cdot y-X(y) \cdot y] d G(x), \quad \forall y \geq y_{\min }
$$


The definition (B10) of the reservation productivity of the firms implies, together with $w(y)=b(y)$, that $X(y)=0$ is implemented by:

$$
f(w)=b(w)+\tau(w)
$$

which proves condition 2. of Proposition 3.

When $X(y)=0$, equations (B10) and (B11) imply that $w(y)+\tau(w(y))=-k(y)+y \int_{0}^{+\infty} x d G(x) \equiv$ $Y^{*}(y)$. The function $w(y)$ being increasing, it follows that $\tilde{Z}(y)=w(y)-\rho$ is an increasing function of $y$. Thus, $\tilde{Z}(y)=w(y)-\rho$ can be written as $y=\tilde{Z}^{-1}(w(y)-\rho)$, which defines, together with $Y^{*}(y)=$ $w(y)+\tau(w(y))$, the function $\tau(w)$ that reads:

$$
\tau(w)=Y^{*}\left[\tilde{Z}^{-1}(w-\rho)\right]-w \quad \text { with } \quad \rho=\int_{y_{\min }}^{+\infty}\left[Y^{*}(y)-\tilde{Z}(y)\right] H[y, \tilde{Z}(y)] d y .
$$

This proves claim 3. of Proposition 3.

\section{Dynamic version of the benchmark model}

\section{C.1 First-best allocations}

Proposition 4 is proved as follows. We first define the discounted values of vacant and filled jobs and the discounted utilities obtained in stationary allocations. This allows us to apply the results obtained in Proposition 1 to characterize the first-best allocations.

Let us first define the discounted value of filled and vacant jobs.

The discounted value of a job occupied by a worker with ability $y$, whose current productivity is $x$, denoted by $Y_{E}(x, y)$, satisfies the arbitrage equation:

$$
r Y_{E}(x, y)=x \cdot y+\mu\left[Y_{E}(y)-Y_{E}(x, y)\right]
$$

where $Y_{E}(y)$ represents the unconditionnal (or ex ante) expected production of a filled job. According to claim 1 of Proposition 1, it is worthwhile keeping employed a type- $(y, z)$ individual if his expected life time production on that job, denoted by $Y_{E}(x, y)$, is higher than the expected life time production of a job seeker, denoted by $Y_{U}(y)$, i.e. it is worthwhile keeping employed the type- $(y, z)$ workers such that $Y_{E}(x, y) \geq Y_{U}(y)$. Therefore, $Y_{E}(y)=\int_{-\infty}^{x_{U}} \max \left[Y_{E}(x, y), Y_{U}(y)\right] d G(x)$. The discounted present value of the net production of a job seeker with ability $y$ during his life time is given by:

$$
r Y_{U}(y)=\lambda\left[-k(y)+Y_{E}\left(x_{U}, y\right)-Y_{U}(y)\right] .
$$

The arbitrage equation $(\mathrm{C} 1)$ implies that $Y_{E}(x, y)$ is strictly increasing with respect to $x$. Therefore, there is a unique threshold value, denoted by $X^{*}(y)$, below which the jobs with idiosyncratic productivity 
$x<X^{*}(y)$ are destroyed. This threshold value satisfies $Y_{E}\left(X^{*}(y), y\right)=Y_{U}(y)$. Furthermore, the existence of this unique threshold implies that:

$$
Y_{E}(y)=\int_{-\infty}^{X^{*}(y)} Y_{U}(y) d G(x)+\int_{X^{*}(y)}^{x_{U}} Y_{E}(x, y) d G(x) .
$$

Since productivity is changing at rate $\mu$, the job destruction rate, denoted by $q^{*}(y)$, is equal to $\mu G\left[X^{*}(y)\right]$. Let $Q^{*}(y)=y \int_{X^{*}(y)}^{x_{U}} x d G(x)$ stand for the instantaneous average production of a worker with ability $y$, equations (C1) and (C3) give:

$$
Y_{E}(y)=\frac{(r+\mu) q^{*}(y) Y_{U}(y)+\mu Q^{*}(y)}{\mu\left[r+q^{*}(y)\right]} .
$$

Setting $x=X^{*}(y)$ in relation $(\mathrm{C} 1)$ arrives at $(r+\mu) Y_{U}(y)=X^{*}(y) \cdot y+\mu Y_{E}(y)$, and eliminating $Y_{E}(y)$ between this last equation and $(\mathrm{C} 4)$ yields the value of the net production of a job seeker with ability $y$ when the productivity threshold takes its first-best value $X^{*}(y)$, denoted by $Y_{U}^{*}(y)$ :

$$
r Y_{U}^{*}(y)=\frac{\left[r+q^{*}(y)\right] X^{*}(y) \cdot y+\mu Q^{*}(y)}{r+\mu} .
$$

From $(\mathrm{C} 1)$ one gets $Y_{E}\left(x_{U}, y\right)-Y_{U}^{*}(y)=\left[x_{U}-X^{*}(y)\right] \cdot y /(r+\mu)$, and importing this expression into (C2) obtains:

$$
r Y_{U}^{*}(y)=\lambda \frac{\left[x_{U}-X^{*}(y)\right] \cdot y-(r+\mu) k(y)}{r+\mu} .
$$

Finally, eliminating $Y_{U}^{*}(y)$ between the two last equations (C5) and (C6) gives the following efficiency condition defining implicitly the optimal threshold value $X^{*}(y)$ :

$$
X^{*}(y)=\frac{\lambda\left[x_{U} \cdot y-(r+\mu) k(y)\right]-\mu Q^{*}(y)}{y\left[\lambda+r+q^{*}(y)\right]}
$$

Substituting this value of $X^{*}(y)$ in (C6) yields another expression for the expected production of a job seeker:

$$
r Y_{U}^{*}(y)=\frac{\lambda}{r+\mu} \frac{\left[r+q^{*}(y)\right]\left[x_{U} \cdot y-(r+\mu) k(y)\right]+\mu Q^{*}(y)}{\lambda+r+q^{*}(y)},
$$

which will be useful in the sequel.

It remains to show that $(\mathrm{C} 7)$ defines a unique value for the productivity threshold $X^{*}(y)$. Integrating by parts $Q^{*}(y)=y \int_{X^{*}(y)}^{x_{U}} x d G(x)$, one gets:

$$
Q^{*}(y)=y\left(x_{U}-X^{*}(y) G\left[X^{*}(y)\right]-\int_{X^{*}(y)}^{x_{U}} G(x) d x\right) .
$$

Importing this expression for $Q^{*}(y)$ in $(\mathrm{C} 7)$ and remembering that $G\left[X^{*}(y)\right]=q^{*}(y) / \mu$, gives:

$$
(r+\lambda) X^{*}(y)=(\lambda-\mu) x_{U}-\lambda(r+\mu) \frac{k(y)}{y}+\mu \int_{X^{*}(y)}^{x_{U}} G(x) d x,
$$


which can be written, after some rearrangements, as:

$$
X^{*}(y)=\frac{\lambda\left[x_{U} \cdot y-(r+\mu) k(y)\right]}{y(r+\mu+\lambda)}-\frac{\mu}{r+\mu+\lambda} \int_{X^{*}(y)}^{x_{U}}[1-G(x)] d x .
$$

The function $\phi(\xi)=\xi+\frac{\mu}{r+\mu+\lambda} \int_{\xi}^{x_{U}}[1-G(x)] d x$ is increasing and satisfies $\phi\left(x_{U}\right)=x_{U}>\frac{\lambda\left[x_{I} \cdot y-(r+\mu) k(y)\right]}{y(r+\mu+\lambda)}$ and $\phi(-\infty)=-\infty$. Thus, $X^{*}(y)$ is unique. This proves claim 1 of Proposition 4.

The planner has to decide who will be allowed to look for a job $\left(s \in S_{A}\right)$ and who will be inactive $\left(s \in S_{I}\right)$. The argument runs the same way as in the static case. Imagine that we can find in $S_{A}$ an agent with $r Y_{U}^{*}(y)<z$. This agent can get the same instantaneous utility level when he is inactive if his stationary instantaneous consumption of the marketable good is decreased by $z$. In terms of discounted present value, deciding that this agent becomes inactive instead of active allows the social planner to win $z / r$ and lose $Y_{U}^{*}(y)$ as forgone production, which yields a net gain equal to $(z / r)-Y_{U}^{*}(y)$. Therefore, the set $S_{A}$ of active agents only comprises individuals such that $r Y_{U}^{*}(y) \geq z$, and the set $S_{I}$ of inactive agents comprises the individuals such that $r Y_{U}^{*}(y)<z$. In other words the participation decision reads, for every date $t \geq 0$ :

$$
\ell^{*}(y, z)=\left\{\begin{array}{l}
0 \text { if } z \leq r Y_{U}^{*}(y) \\
1 \text { otherwise }
\end{array} .\right.
$$

This proves, together with equation (C6), claim 3 of Proposition 4.

Let us now look at discounted utilities in order to characterises the first-best properties of consumptions plans. The instantaneous consumption of a type-s individual in $S_{A}$ is denoted by $c_{E}^{*}(s)$ and $c_{U}^{*}(s)$ when he is respectively employed or searching for a job. The instantaneous consumption of a type-s individual belonging to the set $S_{I}$ of inactive persons is denoted by $c_{I}^{*}(s)$. Inactive individuals achieve a life time utility level equal to $v\left[c_{I}^{*}(s)+z\right] / r$, while the life time expected utility of the type-s individuals assigned to the set $S_{A}$ of job seekers, denoted by $V_{U}(s)$, satisfies the arbitrage equation:

$$
r V_{U}(s)=v\left[c_{U}^{*}(s)\right]+\lambda\left[V_{E}(s)-V_{U}(s)\right]
$$

where the life time expected utility of an employed type-s individual, denoted by $V_{E}(s)$, fulfils:

$$
r V_{E}(s)=v\left[c_{E}^{*}(s)\right]+q^{*}(y)\left[V_{U}(s)-V_{E}(s)\right] .
$$

From these two last equations, one obtains:

$$
r V_{U}(s)=\frac{r+q^{*}(y)}{r+\lambda+q^{*}(y)} v\left[c_{U}^{*}(s)\right]+\frac{\lambda}{r+\lambda+q^{*}(y)} v\left[c_{E}^{*}(s)\right] .
$$

Alike the static case, applying a risk aversion argument to this expression of the expected utility of an agent assigned to $S_{A}$ shows that the first-best allocations necessarily insure all individuals in $S_{A}$ against unemployment risks. Hence, type-s individuals get the same consumption whether employed or 
unemployed. This consumption can be simply denoted by $c^{*}(y, z)$ and the associated utility level is equal to $v\left[c^{*}(y, z)\right] / r$. This proves claim 2 of proposition 4 .

\section{C.2 Second-best allocations}

The optimal tax-subsidy schemes are derived as in the static case. First, the decentralized equilibrium is analyzed. Second, the properties of the optimal tax-subsidy schemes are defined.

\section{C.2.1 Decentralized equilibrium}

The value of a continuing job occupied by a worker with ability $y$ paid a wage $w$, with an idiosyncratic productivity component $x$, denoted by $J_{E}(w, y, x)$, satisfies:

$$
r J_{E}(w, y, x)=x \cdot y-w-\tau(w)+\mu\left[J_{\mu}(w, y)-J_{E}(w, y, x)\right]
$$

where $J_{\mu}(w, y)=\int_{-\infty}^{x_{U}} J_{E}(w, y, x) d G(x)$ stands for the unconditionnal (or ex ante) value of a continuing job occupied by a worker with ability $y$. Firms destroy jobs if and only if their value $J_{E}(w, y, x)$ is lower than their destruction costs $-f(w)$. Therefore, the productivity threshold below wich jobs are destroyed, denoted by $X(w, y)$, is given by:

$$
X(w, y)=\frac{w+\tau(w)-(r+\mu) f(w)-\mu J_{\mu}(w, y)}{y} .
$$

It follows that the unconditional expected value $J_{\mu}(w, y)$ solves:

$$
J_{\mu}(w, y)=\int_{-\infty}^{X(w, y)}-f(w) d G(x)+\int_{X(w, y)}^{x_{U}} J_{E}(w, y, x) d G(x) .
$$

With the help of $(\mathrm{C} 10)$, it is possible to eliminate $J_{E}(w, y, x)$ in the expression of $J_{\mu}(w, y)$. Importing this last expression of $J_{\mu}(w, y)$ in $(\mathrm{C} 12)$ gives the value of the productivity threshold as a function of the wage and the tax schedule:

$$
X(w, y)=\frac{(r+\mu)[w+\tau(w)-r f(w)]-\mu Q(w, y)}{y[r+q(w, y)]} .
$$

In this expression, $q(w, y)$ designates the instantaneous job destruction rate, equal to $\mu G[X(w, y)]$, and $Q(w, y)$ represents the average production of active persons with ability $y$ at each date, that is equal to $\int_{X(w, y)}^{+\infty}(x \cdot y) d G(x)$. Given the wage $w$, the tax schedules $\tau(w)$ and $f(w)$, equation (C12) determines a unique value for $X(w, y)$ - the proof is the same as for the unicity of $X^{*}(y)$ given in appendix C.1.

The net expected profit of an employer offering a contract $w$ to a type- $(y, z)$ worker on a newly opened job, denoted by $J_{0}(w, y)$, is equal to $\Pi_{0}(w, y)-k(y)$, where the gross expected profit $\Pi_{0}(w, y)$ satisfies the arbitrage equation:

$$
r \Pi_{0}(w, y)=x_{U} \cdot y-w-\tau(w)+\mu\left[J_{\mu}(w, y)-\Pi_{0}(w, y)\right]
$$


The Bertrand competition between employers entails that the net expected profit on a new job is driven to zero. Therefore, the equilibrium wage contract offered to the type- $(y, z)$ workers, denoted by $w(y)$, is determined by the free entry condition:

$$
J_{0}(w(y), y)=0 .
$$

At this stage, we can replicate with minor changes what we have done concerning the existence and uniquiness of the Bertrand equilibrium in the static model. Hence we shall assume that the expected profit $J(w, y)$ satisfies the following properties.

\section{Assumption A1}

A1.i) $\forall y,\left\{w \geq 0 \mid J_{0}(w, y)=0\right\} \neq \emptyset$.

A1.ii) $\forall y, \lim _{w \rightarrow+\infty} J_{0}(w, y)<0$.

Alike in the static model, conditions A1.i) and A1.ii) imply that there exists a unique equilibrium wage contract $w(y)$ offered to the type- $(y, z)$ workers, which reads:

$$
\left.w(y)=\sup \{w \geq 0\} \mid J_{0}(w, y)=0\right\}
$$

We can obtain a precise result concerning the monotonicity of the equilibrium wage function $w(y)$ if we add the following assumption.

\section{Assumption A2}

A2.i) $\forall y, J_{0}(w, y)$ is continuous in $w$.

A2.ii) $\forall w, J_{0}(w, y)$ is strictly increasing with $y$.

As in the static model, when assumptions $\mathrm{A} 1$ and $\mathrm{A} 2$ are satisfied the equilibrium wage $w(y)$ is a strictly increasing function of the ability level $y$ (see Proposition 2). It follows that any worker has interest to reveal his true ability. Furthermore, for any wage $w$, the productivity threshold $X(w, y)$ satisfies $J_{E}[w, y, X(w, y)]=-f(w)$. As the arbitrage equations (C13) and (C10) imply $\Pi_{0}(w, y)=J_{E}(w, y, x)+$ $y \frac{x \amalg-x}{r+\mu}$, the equilibrium wage $w(y)$ is characterized by:

$$
X(w(y), y)=x_{U}-(r+\mu) \frac{[f(w(y))+k(y)]}{y},
$$

where the function $X(w, y)$, which defines the productivity threshold for any value of $w$ and $y$, is given by $(\mathrm{C} 12)$.

The type- $(y, z)$ individuals decide to enter into the labor force if and only if searching for a job yields a higher expected utility than staying inactive. At a stationary state, the discounted expected utilities of 
an employed worker and of a job seeker with characteristics $(y, z)$ getting a wage $w$, respectively denoted by $V_{E}(w, y, z)$ and $V_{U}(w, y, z)$, satisfy:

$$
\begin{gathered}
r V_{E}(w, y, z)=v(w)+q(w, y)\left[V_{U}(w, y, z)-V_{E}(w, y, z)\right] \\
r V_{U}(w, y, z)=v[b(w)]+\lambda\left[V_{E}(w, y, z)-V_{U}(w, y, z)\right] .
\end{gathered}
$$

The discounted expected utility of an inactive person is always given by $v(z+\rho) / r$. From $(\mathrm{C} 17)$ and (C18), one obtains:

$$
r V_{U}(w, y, z)=\frac{r+q(w, y)}{r+\lambda+q(w, y)} v[b(w)]+\frac{\lambda}{r+\lambda+q(w, y)} v(w) .
$$

It follows that a type- $(y, z)$ individual decides to enter into the labor market if and only if the participation constraint:

$$
\frac{r+q(w, y)}{r+\lambda+q(w, y)} v[b(w)]+\frac{\lambda}{r+\lambda+q(w, y)} v(w) \geq v(z+\rho)
$$

is fulfilled. This condition implies that only individuals whose taste for leisure $z$ is smaller than the threshold value $Z(w, y)$, defined by

$$
v[Z(w, y)+\rho]=\frac{r+q(w, y)}{r+\lambda+q(w, y)} v[b(w)]+\frac{\lambda}{r+\lambda+q(w, y)} v(w),
$$

belong to the labor force. Therefore, at each date, the participation decision of an individual with characteristics $(y, z)$ who expects to get a wage $w$ reads:

$$
\ell(y, z)=\left\{\begin{array}{lll}
0 & \text { if } \quad z \leq Z(w, y) \\
1 & \text { if } \quad z>Z(w, y)
\end{array}\right.
$$

The knowledge of $Z(y) \equiv Z(w(y), y)$ determines the number of individuals with ability $y$ participating in the labor market, i.e. $n(y)=\int_{-\infty}^{Z(y)} h(y, z) d z \equiv H[y, Z(y)]$. Among those participating individuals, $l(y)$ are actually working and $u(y)$ are looking for a job, thus $l(y)+u(y)=n(y)$. Denoting by $q(y)=q(w(y), y)$ the job destruction rate, the dynamics of employment is defined by the law of motion:

$$
\dot{l}(y)=\lambda[n(y)-l(y)]-q(y) l(y)
$$

where the initial value of $l(y)$ at date $t=0$ is $l_{0}(y)$.

The stationary state flows equilibrium reads $q(y) l(y)=\lambda[n(y)-l(y)]$, which gives:

$$
u(y)=\frac{q(y)}{\lambda+q(y)} n(y)
$$

Eventually, given any stationary tax-subsidy scheme $\{\tau(w), f(w), b(w), \rho\}$ that satisfies Assumptions $\mathrm{A} 1$ and A2, there exists a unique decentralized equilibrium entirely characterized by:

- the reservation productivity $X(y) \equiv X(w(y), y)$ below which jobs are destroyed (equation (C12)), 
- the wage $w(y)$ (equation $(\mathrm{C} 16))$,

- the threshold value of the taste for leisure, $Z(y) \equiv Z(w(y), y)$ below which type- $(y, z)$ individuals participate in the labor market (equation (C21)),

- the initial values of employment $l_{0}(y)$,

- the law of motion (C22) of jobs filled by workers with ability $y$.

The wage $w(y)$, the financial incentives to work $Z(y)$ and the reservation productivity $X(y)$ are forward looking variables which jump on their stationary value whereas employment $l(y)$ is a predetermined variable whose dynamics is defined by $(\mathrm{C} 22)$.

\section{C.2.2 Optimal tax-subsidy schemes}

First, we define the optimal stationary value of $\{w(y), b(y), X(y), \rho\}$ for any second-best financial incentives to work $\tilde{Z}(y)$. Then we find out how this solution can be implemented by the appropriate choice of $\{\tau(w), b(w), f(w), \rho\}$.

In order to characterize the optimal value of $\{w(y), b(y), X(y), \rho\}$ it is useful to decompose the programme of the state in two steps. First, one can define the optimal insurance contract offered to every unemployed worker for any given value of $\{\tilde{Z}(y), X(y), \rho\}$. This optimal contract defines the values of $w(y)$ and $b(y)$ that maximize the discounted present value of the net fiscal gains that the state gets from unemployed workers with ability $y .{ }^{17}$ Second, the optimal value of $\{X(y), \rho\}$ is defined, for any second-best financial incentives to work $\tilde{Z}(y)$.

1) Let us denote by $B_{U}(y)$ and $B_{E}(y)$ the discounted present values of the net fiscal gain that the state gets from unemployed workers and from employees of ability $y$ respectively. These two present values solve the Bellman equations

$$
\begin{aligned}
& r B_{U}(y)=-b(y)+\lambda\left[B_{E}(y)-B_{U}(y)\right], \\
& r B_{E}(y)=\tau(y)+q(y)\left[B_{U}(y)+f(y)-B_{E}(y)\right] .
\end{aligned}
$$

These two equations yield

$$
r B_{U}(y)=-\frac{r+q(y)}{r+\lambda+q(y)} b(y)+\frac{\lambda}{r+\lambda+q(y)}[\tau(y)+q f(y)] .
$$

\footnotetext{
${ }^{17}$ This presentation, which is useful to interpret our results, is in line with the literature on optimal unemployment insurance in a dynamic framework (see Hopenhayn and Nicolini, 1997, Ljungqvist and Sargent, 2000). It is equivalent to assume that the state maximizes the expected utilities conditional on abilities $y$ but not on the employment status at date zero. In that case, the state maximizes the weighted sum of the discounted utilities of the employed workers - with weight $l_{0}(y) / n(y)$ - and of the unemployed workers - with weight $1-l_{0}(y) / n(y)-$ with abitlity $y$, subject to a budget constraint.
} 
Eliminating $X(w, y)$ between relations $(\mathrm{C} 12)$ and $(\mathrm{C} 16)$ arrives at

$$
\tau(y)+q(y) f(y)=\frac{[r+q(y)]\left[x_{U} \cdot y-(r+\mu) k(y)\right]+\mu Q(w(y), y)}{r+\mu}-w(y) .
$$

By analogy with (C8), let us defined $Y_{U}(y)$ by

$$
r Y_{U}(y)=\frac{\lambda}{r+\mu} \frac{[r+q(y)]\left[x_{U} \cdot y-(r+\mu) k(y)\right]+\mu Q(w(y), y)}{\lambda+r+q(y)} .
$$

The quantity $Y_{U}(y)$ represents the expected net production of a job seeker when the productivity threshold is equal to $X(w(y), y)$, while the quantity $Y_{U}^{*}(y)$ defined by $(\mathrm{C} 8)$ represents the expected net production of a job seeker when the productivity threshold takes its first best optimal value $X^{*}(y)$. Equation $(\mathrm{C} 25)$ can be rewritten as

$$
\tau(y)+q(y) f(y)=\frac{\lambda+r+q(y)}{\lambda} r Y_{U}(y)-w(y)
$$

and the net fiscal gain $B_{U}(y)$ takes the following form:

$$
r B_{U}(y)=r Y_{U}(y)-\frac{\lambda w(y)+[r+q(y)] b(y)}{\lambda+r+q(y)} .
$$

Accordingly, the optimal contract offered to the unemployed workers with ability $y$ solves

$$
\max _{\{w(y), b(y)\}} r Y_{U}(y)-\frac{\lambda w(y)+[r+q(y)] b(y)}{\lambda+r+q(y)}
$$

subject to

$$
\frac{r+q(y)}{r+\lambda+q(y)} v[b(y)]+\frac{\lambda}{r+\lambda+q(y)} v(w(y)) \geq v[\tilde{Z}(y)+\rho] .
$$

It can be easily checked that the solution of this program yields $w(y)=b(y)=\tilde{Z}(y)+\rho, \forall y \geq y_{\text {min }}$.

2) Let us denote by $p(y)=\int_{-\infty}^{+\infty} h(y, z) d z$ the size of the population of individuals with ability $y$. The budget constraint of the state reads

$$
\int_{y_{\min }}^{+\infty}\left[r B_{U}(y)\left[n(y)-l_{0}(y)\right]+r B_{E}(y) l_{0}(y)\right] d y \geq \int_{y_{\min }}^{+\infty} \rho[p(y)-n(y)],
$$

which can be rewritten as:

$$
\int_{y_{\min }}^{+\infty}\left[r Y_{U}(y) \frac{\lambda n(y)+r l_{0}(y)}{\lambda}-\tilde{Z}(y) n(y)\right] d y \geq \rho .
$$

For any second-best financial incentives to work $\tilde{Z}(y)$, the optimal value of $\{X(y), \rho\}$ solves $\max _{\{X(y), \rho\}} \rho$ subject to $(\mathrm{C} 27)$. As $n(y)=\int_{-\infty}^{\tilde{Z}(y)} h(y, z) d z$ depends on $X(y)$ nor on $\rho$, the optimal productivity threshold must maximize the expected production $Y_{U}(y)$ defined by relation (C26). It is straightforward to show that such a maximization arrives at $X(y)=X^{*}(y)$ - defined in equation $(\mathrm{C} 7)$-, i.e. the productivity 
threshold is the same as in the first best environment. Consequently, the expected production $Y_{U}(y)$ reaches the level $Y_{U}^{*}(y)$ defined by $(\mathrm{C} 8)$. Finally, optimal values of $\tilde{Z}(y)$ and $\rho$ must be such that the budget constraint $(\mathrm{C} 27)$ is binding. Simple manipulations allows us to write this budget constraint a follows:

$$
\int_{y_{\min }}^{+\infty}\left[r Y_{U}^{*}(y)-\tilde{Z}(y)\right] H[y, \tilde{Z}(y)] d y=\rho_{D} \quad \text { with } \rho_{D}=\rho-r Y_{U}^{*}(y) \frac{r}{\lambda} l_{0}(y)
$$

At this stage, it has been proved that the optimal value of $\{w(y), b(y), X(y), \rho\}$ satisfies $b(y)=w(y)$ and $X(y)=X^{*}(y)$ for any second-best financial incentive to work $\tilde{Z}(y)$ that satisfies the budget constraint (C28). Formally, this latter constraint is equivalent to the budget constraint of the static model - see condition 3 of Proposition 3 - where $Y^{*}(y)$ and $\rho$ have been replaced respectively by $r Y_{U}^{*}(y)$ and $\rho_{D}$. As in the static model, Theorem 3 of Laroque (2005), which completely characterizes the second-best optimal financial incentives to work $\tilde{Z}(y)$, such that $\tilde{Z}(y) \leq r Y_{U}^{*}(y)$, applies.

Let us find out how this solution $\{w(y), b(y), X(y), \rho\}$ can be implemented by the appropriate choice of $\{\tau(w), b(w), f(w), \rho\}$. The equality $b(y)=w(y)$ is merely implemented by $b(w)=w$ which proves condition 1. of Proposition 5.

Moreover, when $X(y)=X^{*}(y),(\mathrm{C} 16)$ shows that:

$$
(r+\mu) k(y)=y\left[x_{U}-X^{*}(y)\right]-(r+\mu) f(w(y)) .
$$

Using this equation together with relation (C7) that defines the optimal productivity threshold arrives at:

$$
X^{*}(y)=\frac{\lambda(r+\mu) f(w(y))-\mu Q^{*}(y)}{y\left[r+q^{*}(y)\right]} .
$$

Comparing this equation with (C12) yields

$$
(r+\lambda) f(w)=w+\tau(w)
$$

which proves condition 2. of Proposition 5.

When $X(y)=X^{*}(y),(r+\lambda) f(w)=w+\tau(w)$ and $b(w)=w$, the wage equation (C16) implies, together with the definition $(\mathrm{C} 6)$ of $Y_{U}^{*}(y)$, that $w(y)+\tau(y)=\frac{r+\lambda}{\lambda} r Y_{U}^{*}(y)$. The condition $\tilde{Z}(y) \leq r Y_{U}^{*}(y)$ is then identical to $\tau(y) \geq-w(y)+\frac{r+\lambda}{\lambda} \tilde{Z}(y)$, as $\tilde{Z}(y)=w(y)-\rho$ and $w(y)=b(y)$ the condition $\tilde{Z}(y) \leq r Y_{U}^{*}(y)$ implies that optimal second best policies must satisfy $\lambda \tau(w)+(r+\lambda) \rho \geq r b(w)$. Finally, the function $w(y)$ being increasing, it follows that $\tilde{Z}(y)=w(y)-\rho$ is an increasing function of $y$. Thus, $\tilde{Z}(y)=w(y)-\rho$ can be written as $y=\tilde{Z}^{-1}(w(y)-\rho)$, which defines, together with $\frac{r+\lambda}{\lambda} r Y_{U}^{*}(y)=w(y)+\tau(y)$, the function $\tau(w)$ that reads:

$\tau(w)=\frac{r+\lambda}{\lambda} r Y_{U}^{*}\left[\tilde{Z}^{-1}(w-\rho)\right]-w \quad$ with $\quad \rho=\int_{y_{\min }}^{+\infty}\left[r Y_{U}^{*}(y) \frac{\left[n(y)-l_{0}(y)\right] \lambda+r l_{0}(y)}{\lambda}-\tilde{Z}(y) n(y)\right] d y$ This proves claim 3. of Proposition 5. 


\section{C.3 Computation of the loss induced by tax-subsidy schemes without layoff taxes}

In the sequel we shall deal only with economies whose starting point corresponds to the stationary equilibrium. When $l_{0}(y)$ is taken equal to its stationary value, $\lambda n(y) /(q+\lambda)$, using equation $(\mathrm{C} 27)$ one arrives at the following expression of the intertemporal budget constraint of the state:

$$
\int_{y_{\min }}^{+\infty}[F(y)-Z(y)] H[y, Z(y)] d y=\rho
$$

with

$$
\begin{aligned}
F(y) & =\frac{\lambda+r+q(y)}{\lambda+q(y)} r Y_{U}(y) \\
& =\frac{\lambda}{\lambda+q(y)}\left[\frac{r+q(y)}{r+\mu} x_{U} \cdot y-[r+q(y)] k(y)+\frac{\mu}{r+\mu} Q(y)\right],
\end{aligned}
$$

where $q(y)=\mu G(X(y))$ and $Q(y)=\int_{X(y)}^{x_{U}}(x \cdot y) d G(x)$.

Under such circumstances, assuming that $H(y, Z)$ is log-concave ${ }^{18}$ with respect to $Z$, the Laffer bound is defined by a unique value of financial incentives to work for each ability type $y$, denoted by $\tilde{Z}(y)$, such that

$$
\tilde{Z}(y)=\sup \arg \max _{Z}[F(y)-Z] H(y, Z),
$$

for any given finite value $X(y)<x_{U}$ - see Laroque, 2005, Proposition 5. The Laffer bound is computed in two different cases.

- First, it is assumed that there is no layoff taxes. In that case, equation $(\mathrm{C} 16)$ implies that $X(y)=$ $x_{U}-(r+\mu) \frac{k(y)}{y}$. The financial incentives to work solve (C32) with this value of $X(y)$. Let us denote by $\tilde{Z}_{0}(y)$ the solution, the income guarantee, denoted by $\rho_{0}$, satisfies

$$
\rho_{0}=\int_{y_{\min }}^{+\infty}\left[F(y)-\tilde{Z}_{0}(y)\right] H\left[y, \tilde{Z}_{0}(y)\right] d y,
$$

where $F(y)$ is defined in equation (C31) and $X(y)=x_{U}-(r+\mu) \frac{k(y)}{y}$.

- Second, it is assumed that the layoff tax schedule is designed optimaly. This implies that $X(y)=$ $X^{*}(y)$, defined in equation $(\mathrm{C} 7)$. The financial incentives to work solve $(\mathrm{C} 32)$ with this value of $X(y)$. Let us denote by $\tilde{Z}^{*}(y)$ the solution, the income guarantee, denoted by $\rho^{*}$, satisfies

$$
\rho^{*}=\int_{y_{\min }}^{+\infty}\left[F(y)-\tilde{Z}^{*}(y)\right] H\left[y, \tilde{Z}^{*}(y)\right] d y,
$$

where $F(y)$ is defined in equation (C31) and $X(y)=X^{*}(y)$.

\footnotetext{
${ }^{18} H(y, Z)$ is $\log$-concave with respect to $y$ and $Z$ since $y$ and $Z$ have independent Log Normal Distributions as it is assumed in our calibration exercises.
} 